\title{
Plastic Hinge Analysis for Lightly Reinforced and Unconfined
}

\section{Concrete Structural Walls}

\author{
Ryan D. Hoult ${ }^{1,4}$, Helen M. Goldsworthy ${ }^{2,4}$, Elisa Lumantarna ${ }^{3,4}$ \\ 1. Corresponding Author. PhD Candidate, Department of Infrastructure Engineering, \\ University of Melbourne, Parkville, 3010, Australia. Email: ryan.hoult@unimelb.edu.au. \\ $\mathrm{Ph}:+61401955374$ \\ 2. Associate Professor, Department of Infrastructure Engineering, University of Melbourne, \\ Parkville, 3010, Australia. Email: helenmg@unimelb.edu.au \\ 3. Lecturer, Department of Infrastructure Engineering, University of Melbourne, Parkville, \\ 3010, Australia. Email: elu@unimelb.edu.au \\ 4. Bushfire and Natural Hazards Cooperative Research Centre, Melbourne, Australia
}

\section{Abstract}

Poor performance of lightly reinforced and unconfined concrete structural walls have been observed in recent earthquake events. This research investigates the displacement capacity of such walls by comparing the results of a series of state-of-the-art finite element analyses for a range of different structural walls to that estimated using plastic hinge analyses. The common expressions used in estimating the yield curvature, yield displacement and plastic displacement are scrutinised for these types of walls. Some recommendations are given to improve the prediction of the displacement capacity of lightly reinforced and unconfined rectangular and C-shaped walls for flexural actions using a plastic hinge analysis. Importantly, a parameter has been recommended to be used in a "modified" approach for estimating the nominal yield displacement of lightly reinforced concrete walls. Different expressions are also recommended depending on the amount of longitudinal reinforcement used in the wall in comparison to that required to initiate secondary cracking. This is important for providing better estimations of the displacement capacity of RC structural wall buildings in low-to-moderate seismic regions such that vulnerability studies can be conducted.

\section{Introduction}

The moment magnitude $\left(M_{w}\right) 6.2$ aftershock event in Christchurch on February $22^{\text {nd }}, 2011$, the most damaging event in the Canterbury earthquake sequence, highlighted the poor behaviour that can be exhibited by lightly reinforced and unconfined reinforced concrete (RC) walls. For example, some of the walls in the Gallery Apartments building had a single, primary crack form at their base (Figure 1) rather than the well distributed cracks (over a plastic hinge zone) that were expected to form. As 
shown in Figure 1b, it was common to find fracturing of the reinforcing bars that crossed this crack

34 due to the concentration of tensile strains in the vicinity of the crack (Henry, 2013; Sritharan et al., 2014). 'The building's [Gallery Apartments] overall damage state may be described as being at near collapse. A potentially catastrophic failure might have been observed for a slightly longer duration of severe ground shaking' (Morris et al., 2015). This type of performance in RC walls was also observed during the Chilean Earthquake of 1985 in the El Faro building (Wood et al., 1991; Wood, 1989). The investigation by Wood et al. (1991) on the El Faro building provided a 'rare, documented failure of a structural wall-system', with failure and ultimately collapse of the building occurring after the longitudinal reinforcement fractured in a first-story wall. To the authors' knowledge, this was the first documented case of a single-crack-failure in a $\mathrm{RC}$ wall from an earthquake event, where this single-crack phenomenon can be attributed to the low amount of longitudinal reinforcement used in the wall (CERC, 2012; Hoult et al., 2017).
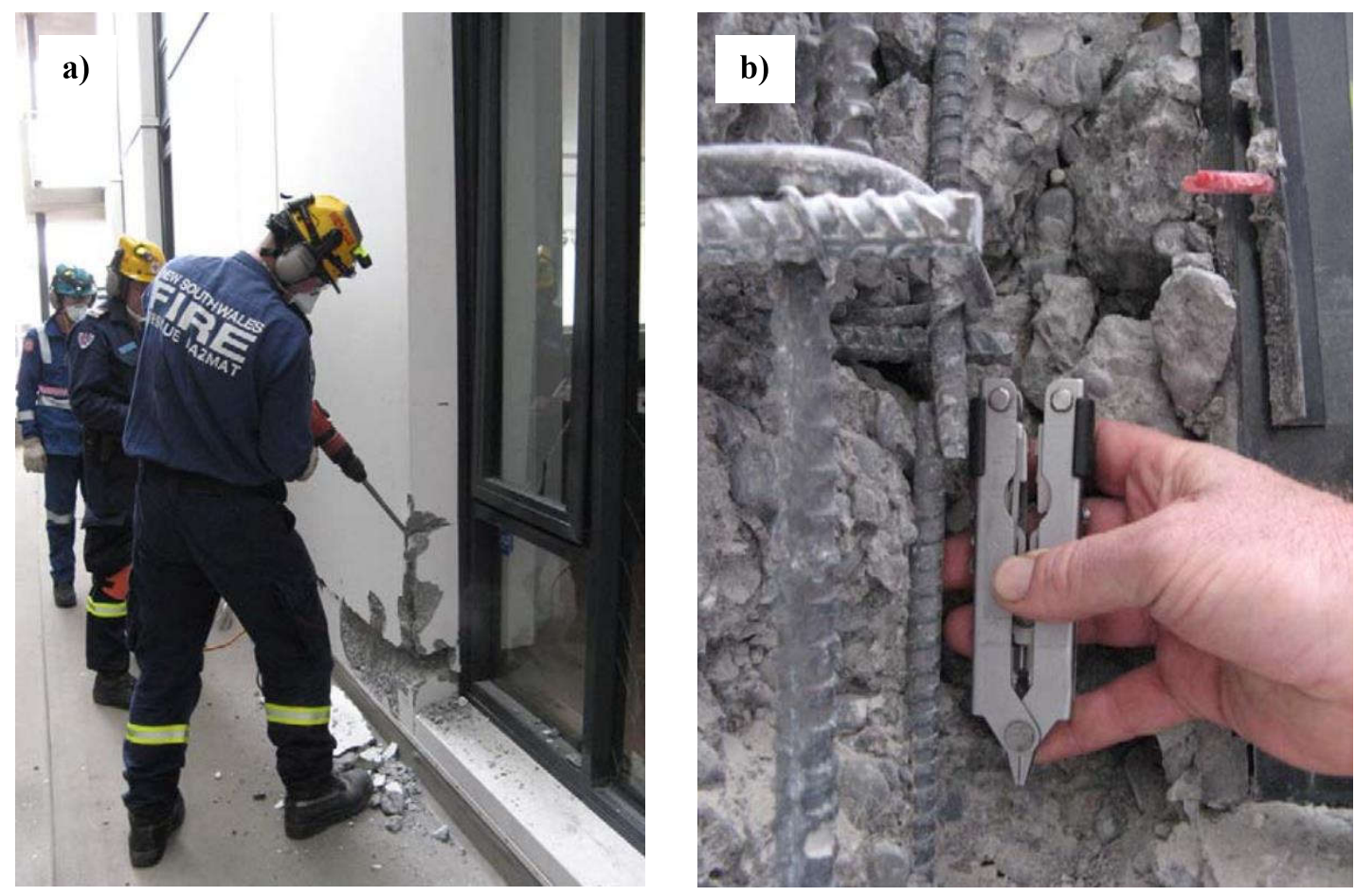

Figure 1 Single-crack failure observed in the Gallery Apartments building, Christchurch (a) concrete removal and (b) fractured bar (Sritharan et al., 2014)

47 The collapse of the Pyne Gould building was another example of poor building performance observed from the Christchurch earthquake. The building was reliant on $\mathrm{RC}$ walls for its lateral load resisting 
system, which formed a core surrounding stairs and lifts. The core walls were lightly reinforced and unconfined, having a single layer of deformed $16 \mathrm{~mm}$ bars spaced at $381 \mathrm{~mm}$ for both the horizontal and longitudinal reinforcement (Beca, 2011). The failure, according to Beca (2011), occurred between levels one and two due to the vertical reinforcement in the west wall of the core yielding in vertical tension and subsequently fracturing due to the concentration of strains at a suspected single,

54 primary crack. Furthermore, the core, continuing to deform to the east, reaching its unconfined compression capacity in the east wall of the core. This poor behaviour of the core walls resulted in large deformations of the gravity system (frames) and eventually led to a "pancake"-type collapse of the building. It is important to note that the Christchurch earthquake sequence had similar mechanisms to that associated with intraplate earthquake events in Australia, i.e. it was a reverse

59 faulting mechanism which was shallow and had a high stress-drop (Bradley et al., 2014; Brown \&

60 Gibson, 2004; Goldsworthy, 2012). Buildings in Australia and other low-to-moderate seismic regions

61 commonly use RC structural walls as their lateral load resisting system. The low standard of detailing

62 required in the current (and previous) concrete structures standards in Australia (AS 3600), coupled with the low return period earthquake typically used in design, has resulted in the great majority of these walls being lightly reinforced and unconfined. The failures observed in Christchurch are a forewarning of the catastrophic structural damage that would potentially occur in Australia due to the poor behaviour of RC structural wall buildings if a similar magnitude event were to occur near a densely-populated area.

Until recently, experimental seismic testing typically focused on RC walls that were rectangular in cross-section, well confined in the boundary regions and highly reinforced (Cardenas \& Magura,

70 1972; Oesterle et al., 1979; Oesterle et al., 1976; Wight et al., 1984). Furthermore, while rectangular

71 walls are commonly utilised on the perimeters of buildings (e.g. "peripheral walls"), many RC walls

72 (or cores) are non-rectangular due to architectural requirements (Belletti et al., 2013; Smyrou et al.,

73 2013). For example, C-shaped walls are commonly found enclosing a service core, elevators, stairs,

74 or toilets in buildings (Beyer et al., 2008a). There have been several experimental programs to assess

75 the seismic performance of C-shaped (or "U-shaped") RC walls detailed to regions of high seismicity 
in the past decade or so (Beyer et al., 2008b; Constantin \& Beyer, 2016; Ile \& Reynouard, 2005;

77 Lowes et al., 2013; Pegon et al., 2000; Sittipunt \& Wood, 1993). However, despite being popular in construction, there have been relatively few studies conducted on the seismic performance of Cshaped walls with the type of detailing that would commonly be found in Australia and other low-tomoderate seismic regions, and there is a lack of experimental data for these types of walls. Moreover, the plentiful of plastic hinge analysis expressions used for estimating the displacement capacity of cantilever walls have been primarily calibrated to well-detailed RC elements. Thus, it is possible that these same expressions cannot accurately estimate the displacement capacity of lightly reinforced and unconfined walls found in low-to-moderate seismic regions.

The aim of this research is to assess the validity of using plastic hinge analyses (PHA) to estimate the displacement capacity of lightly reinforced and unconfined walls. Two different wall shapes are used for this assessment; rectangular and C-shaped. An extensive number of finite element modelling results, previously used for analysing the equivalent plastic hinge length (Hoult et al., 2017, 2018), will be used to examine the displacement capacity and for comparison to the estimate produced with the crude method of PHA. Expressions are ultimately recommended to be used in PHA for lightly reinforced concrete walls, which are also dependent on the amount of longitudinal reinforcement ratio used in the wall (compared to the minimum required to cause secondary cracking).

The results from this study will provide vital information for the vulnerability studies of RC buildings that are being carried out by the authors within the earthquake mitigation component of the Australian CRC (Cooperative Research Centre) for Bushfires and Natural Hazards.

\section{Plastic Hinge Analysis}

For the purposes of seismic design and assessment, it is common to use a bilinear approximation of the force-displacement response of RC walls (Priestley et al., 1996), as illustrated in Figure 2. A PHA is one of the most widely used and simplest methods for calculating the force-displacement capacities of RC members (Almeida et al., 2016). The PHA acknowledges that the top displacement of a cantilever wall structure is the summation of the deformation components primarily due to flexure, 
102 shear and slipping. These deformation components can be used to calculate the yield displacement

$103\left(\Delta_{y}\right)$ and plastic displacement $\left(\Delta_{p}\right)$, as illustrated in Figure 2. The ultimate displacement $\left(\Delta_{u}\right)$ of the

104 cantilever RC wall is the summation of $\Delta_{y}$ and $\Delta_{p}$. The ultimate capacity (or failure) of RC walls in

105 some research has been taken at the point at which the maximum strength is reduced by $20 \%$

106 (Krolicki et al., 2011; Park, 1989). However, as illustrated in Figure 2, the non-ductile failure that is

107 typically expected in unconfined walls with the details commonly found in low-to-moderate seismic

108 regions is likely to correspond to a more abrupt reduction in strength. Therefore, "failure" here is

109 deemed to correspond to material strain limits in the reinforcing steel and concrete for the "collapse

110 prevention" performance level for unconfined RC walls. This corresponds to strains limits of -0.003

111 and 0.05 in the concrete $\left(\varepsilon_{c}\right)$ and steel $\left(\varepsilon_{s}\right)$, respectively, which were subsequently used as the failure

112 strain limits in the studies conducted by Hoult et al. (2017) and Hoult et al. (2018) for rectangular and

113 C-shaped RC walls respectively. In short, this concrete strain limit for unconfined RC walls represent

114 the concrete reaching close to its ultimate capacity. Furthermore, the steel strains are limited to

115 prevent collapse due to low cycle fatigue (due to inelastic cycles in main event plus aftershocks) and

116 out-of-plane buckling on reversal of load. This has been calculated as $0.6 \varepsilon_{s u}$ as per the

117 recommendations in Priestley et al. (2007), where the uniform elongation strain $\left(\varepsilon_{s u}\right)$ has been taken as

118 an approximate mean value given in Menegon et al. (2015) for D500N bars. It should be noted that

119 these values have been chosen for assessment, where more conservative values could be warranted for

120 the reinforcing steel in design, such as 0.03 , which corresponds to 0.6 of the nominal uniform

121 elongation strain for N-type reinforcing steel (Standards Australia/New Zealand, 2001). An even

122 more stringent tension strain limit for the design of $\mathrm{RC}$ walls could also warranted to mitigate against

123 out-of-plane buckling of the wall. 


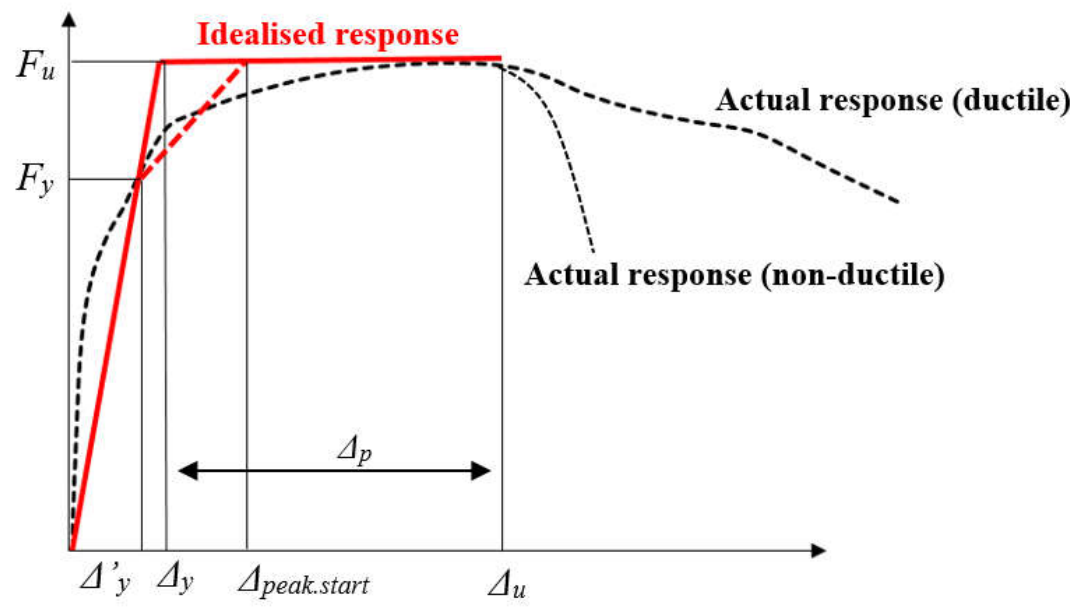

126 In this section, a review is undertaken for some of the equations that have been recommended in the

127 literature for determining the displacement capacity of RC walls using the PHA method. These PHA

128 equations will ultimately be scrutinised as to their applicability for lightly reinforced and unconfined

129 rectangular and C-shaped walls. It should be noted that the research conducted here is primarily

130 focused on improving the displacement capacity estimates for these types of walls due to flexure. The

131 authors acknowledge the potential for other contributions to the overall displacement capacity of a RC

132 wall, such as shear and slip, or other modes of failure, such as out-of-plane buckling due to poor

133 confinement. However, due to both lack of experimental evidence and limitations of the PHA

134 method, the primary focus of this research is to investigate the displacement capacity of these types of

135 walls assuming the performance is governed by flexure.

\section{$136 \quad 2.1$ Yield Displacement}

137 The displacement of the wall at first yield $\left(\Delta_{y}^{\prime}\right)$ is defined as when the outermost reinforcing bar in the 138 extreme tension fibre region of the $\mathrm{RC}$ section first reaches the strain at yield. The line that extends

139 from this point to the nominal yield $\left(\Delta_{y}\right)$ point (Figure 2$)$ is calculated using Equation 1.

$$
\Delta_{y}=\frac{\Delta^{\prime}{ }_{y} F_{u}}{F_{y}}
$$


140 For moderate to slender rectangular RC walls with high aspect ratios $\left(A_{r}>2\right)$ the contribution of shear

141 deformations and displacements due to slip are commonly ignored due to the negligible amount they

142 contribute to the overall displacement capacity (Wibowo et al., 2013). However, the shear deformations

143 can make an important contribution to the overall displacement of non-rectangular RC sections, such

144 as C-shaped walls, even if the $A_{r}$ is greater than 2 (Beyer et al., 2008b; Constantin \& Beyer, 2016;

145 Zhang \& Li, 2014). A commonly used expression for estimating $\Delta_{y}$ is given in Priestley et al. (2007)

146 with Equation 2. Importantly, this expression has been derived assuming the curvature profile up the

147 height of the wall is a 'straight line from the yield value at the base to zero at the top of the wall'

148 (Priestley et al., 2007).

$$
\Delta_{y}=\frac{\Phi_{y} H_{e}^{2}}{2}\left(1-\frac{H_{e}}{3 H_{n}}\right)
$$

149 where $\Phi_{y}$ is the nominal yield curvature, $H_{e}$ is the effective height of the cantilever wall and $H_{n}$ is the 150 height of the cantilever wall at roof level.

151 However, Beyer (2007) recognised that the assumption of the linear curvature profile 'tends to 152 overestimate the flexural displacements in the upper part of the wall'. It is also probable that the linear 153 curvature assumption is vastly different to the realistic curvature profiles obtained from lightly 154 reinforced concrete walls when pushed to their ultimate limit state. This is particularly true for lightly 155 reinforced walls that exhibit a single, primary crack, where the strains (at yield) will be concentrated 156 over a small height at the base of the wall. To overcome this, a new approach was proposed in Beyer 157 (2007) to calculate the yield displacement based on the flexural, strain penetration and shear 158 deformation components. A factor (defined here as $k_{c r}$ ) was also introduced by Beyer (2007), and later 159 revised by Constantin (2016), to account for the actual height of the wall that is estimated to be cracked, 160 which is illustrated in Figure 3. Thus, the yield displacement expression for a RC wall as proposed by 161 Beyer (2007) is in the form of Equation 3, which includes the contributions due to shear deformations 162 using the shear-to-flexure deformation ratio $\left(\Delta_{s} / \Delta_{f}\right)$. 


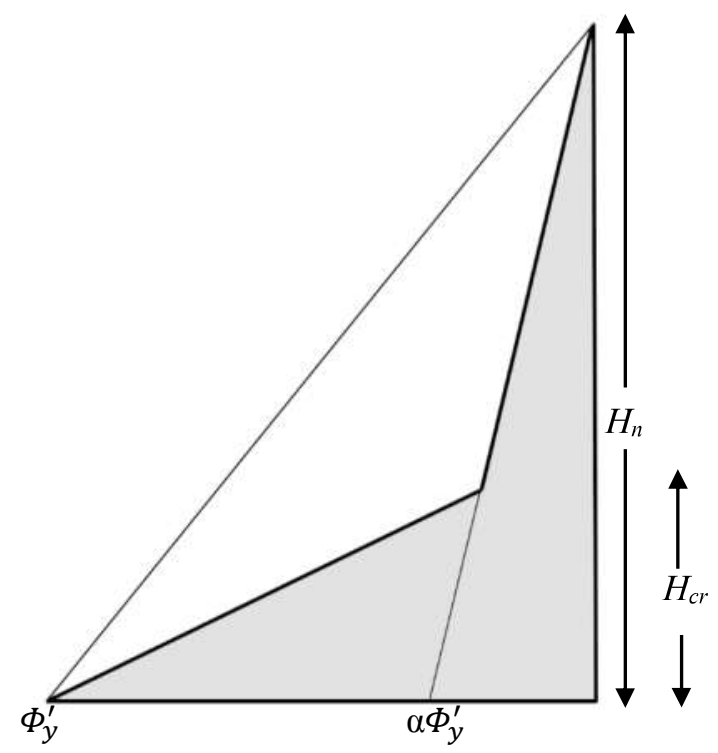

164 Figure 3 Factors proposed by Beyer (2007) and Constantin (2016) for calculating the yield displacement

$$
\Delta_{y}=\Phi_{y}\left(\frac{k_{c r}}{3} H_{n}^{2}+L_{y p} H_{n}\right)\left(1+\frac{\Delta_{s}}{\Delta_{f}}\right)
$$

where $L_{y p}$ is the yield strain penetration length (a parameter discussed further in Section 2.2). The

166 expression for $k_{c r}$ is given in Constantin (2016) in the form of Equation 4.

$$
k_{c r}=\alpha+0.5(1-\alpha)\left(\frac{3 H_{c r}}{H_{n}}-\frac{H_{c r}^{2}}{H_{n}^{2}}\right)
$$

where $\alpha$ is the ratio of cracked to uncracked flexural wall stiffness $\left(E_{c} I_{c r} / E_{c} I_{g}\right)$ and $H_{c r}$ is the height of

168 the cracked wall, which can be estimated using Equation 5. It should be noted that the stiffness of the 169 cracked section $\left(E_{c} I_{c r}\right)$ can be estimated using the ratio of the moment to curvature at first yield $\left(M_{y}^{\prime} /\right.$ $\left.170 \Phi_{y}^{\prime}\right)$.

$$
H_{c r}=\max \left(L_{w},\left(1-\frac{M_{c r}}{M_{y}^{\prime}}\right) H_{n}\right)
$$

171 where $M_{c r}$ is the cracking moment (Equation 6).

$$
M_{c r}=\frac{\left(f_{c t . f}^{\prime}+\frac{P}{A_{g}}\right) I_{g}}{y}
$$


where $P$ is the axial load, $A_{g}$ is the gross section area, $I_{g}$ is the gross second moment of inertia of the

173 wall cross-section, $y$ is the distance from the neutral axis to the extreme tension fibre region and $f_{c t . f}$ is

174 the mean value of the flexure tensile strength of the concrete.

175 It should be noted that in some RC wall cases, when a very low amount of longitudinal reinforcing 176 steel has been used, the $M_{c r}$ could be greater than $M_{y}^{\prime}$. Therefore, $H_{c r}$ (Equation 5) is taken as $L_{w}$ for 177 these types of walls. Although this value of $H_{c r}\left(\right.$ of $\left.L_{w}\right)$ is unrealistic, given that these types of walls 178 are more likely to produce a single, primary crack at the base, the proposed modification factor 179 (discussed later in Sections 4.1.2 and 4.2.2) rectifies this problem.

180 The curvature at first yield $\left(\Phi_{y}^{\prime}\right)$ can be calculated from a sectional analysis (or "moment-curvature 181 analysis"), where Equation 7 corresponds to the curvature at which the outer-most longitudinal 182 reinforcing bar in the extreme tension fibre region reaching the yield strain $\left(\varepsilon_{y}\right)$. The yield strain can 183 be determined from the yield stress $\left(f_{y}\right)$ and the Young's modulus $\left(E_{s}\right)$ of the reinforcing steel $\left(\varepsilon_{y}=\right.$ $\left.184 f_{y} / E_{s}\right)$. The nominal yield curvature $\left(\Phi_{y}\right)$ can thus be calculated using Equation 8 . Moreover, the 185 expression shown in Equation 9, which was first suggested by Priestley and Kowalsky (1998), can be 186 used to estimate the $\Phi_{y}$ of a RC wall, where the 'proportionality factor' $\left(K_{l}\right)$ is said to be largely 187 depend on the longitudinal reinforcement layout and the shape of the cross section of the wall.

$$
\begin{aligned}
& \Phi_{y}^{\prime}=\frac{M_{y}}{E_{c} I_{e f f}} \\
& \Phi_{y}=\Phi_{y}^{\prime}\left(\frac{M_{u}}{M_{y}}\right)
\end{aligned}
$$

188 where $M_{u}$ is the ultimate moment capacity of the RC section.

$$
\Phi_{y}=\frac{K_{1} \varepsilon_{s y}}{L_{w}}
$$

189 Several researchers have given recommendations on the value of $K_{l}$ that should be used to estimate

$190 \Phi_{y}$ (Equation 9) for a range of wall shapes. For example, a commonly used value of $K_{l}$ for RC

191 rectangular walls is 2.0, which has been derived from analytical and experimental studies (Paulay,

192 2002; Priestley \& Kowalski, 1998). The $K_{I}$ value of 2.0 for RC rectangular walls has subsequently 
193 been used in the PHA method outlined in Priestley et al. (2007). However, as discussed in Priestley

194 and Kowalski (1998), the relationship for yield curvature with a $K_{l}$ factor 2.0 'should not be

195 extrapolated beyond the range $300 \leq f_{y} \leq 500 \mathrm{MPa}$ nor beyond the limits of longitudinal steel ratio',

196 which were between $1.00 \% \leq \rho_{w v} \leq 4.00 \%$. Given that the lower characteristic value of the yield

197 stress $\left(f_{y}\right)$ of D500N reinforcing bars commonly used in Australia is $500 \mathrm{MPa}$ (Standards

198 Australia/New Zealand, 2001), the actual value of $f_{y}$ will typically be higher than $500 \mathrm{MPa}$.

199 Moreover, the majority of $\mathrm{RC}$ walls found in this region will have longitudinal reinforcement ratios

200 lower than 1.00\% (Albidah et al., 2013; Wibowo et al., 2013). Adebar and Lorzadeh (2012) also

201 discuss that it is rare for RC walls to have a $\rho_{w v}$ higher than $1.00 \%$. Hence the equation for estimating

202 the nominal yield curvature for rectangular walls in Australia needs further investigation.

203 Beyer (2007) recognised that $K_{l}$ factors had not been derived explicitly for U-shaped (or C-shaped)

204 RC sections. However, Beyer (2007) realised it was possible that the $K_{l}$ factors for I-shaped and T-

205 shaped walls could 'serve as approximates' for C-shaped walls and bending about the major and

206 minor axes, respectively. Following the research by Beyer (2007), some values have been proposed

207 by Sullivan et al. (2012) for C-shaped walls, given in Table 1. It should be noted that 'Major'

208 corresponds to bending of the C-shaped wall in the direction parallel to the web (about the major

209 axis), whereas $\mathrm{WiC}$ and $\mathrm{WiT}$ correspond to the wall bending in the direction parallel to the flanges

210 (about the minor axis) with web in compression and web in tension, respectively. These different

211 modes of bending for a C-shaped wall are illustrated in Figure 4, where the shaded regions of the wall

212 are the idealised compression zones. Testing of the seismic performance of C-shaped walls designed

213 to regions of high seismicity from Constantin (2016) found that these proposed values corresponded

214 well to experimental observations.

\begin{tabular}{lccc}
\hline & Major & WiC & WiT \\
\hline Sullivan et al. (2012) & 1.40 & 1.40 & 1.80 \\
\hline
\end{tabular}




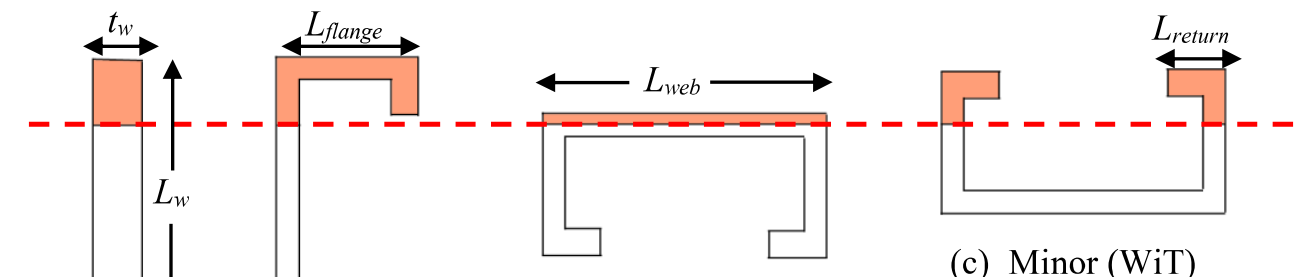

(d) Minor (WiC)

(c) Minor (WiT)

(a) Major (b) Major

\section{Figure 4 Different modes of bending for (a) rectangular walls and (b-d) C-shaped wall, with idealised} neutral axis for high levels of loading

\subsection{Plastic Displacement}

To estimate the plastic deformation $\left(\Delta_{p}\right)$, the strains and corresponding curvatures need to be determined, and these will vary considerably up the height of a cantilevered wall. However, it is common practice to simply assume that the inelastic curvature is uniform for a height above the base that is equivalent to the plastic hinge length $\left(L_{p}\right)$ (Fenwick \& Dhakal, 2007). This is a reasonable approximation and is utilised in the equations proposed by Priestley et al. (2007) for the displacement profile of a cantilevered wall in Equation 10. It should be noted that the shear-to-flexure ratio has been included in Equation 10, which was also used by Constantin (2016) for the plastic displacement of C-shaped walls; for rectangular walls with $A_{r}$ greater than 2, it is assumed that the $\Delta_{s} / \Delta_{f}$ is equivalent to zero (negligible).

$$
\Delta_{p}=L_{p}\left(\Phi_{u}-\Phi_{y}\right) H_{e}\left(1+\frac{\Delta_{s}}{\Delta_{f}}\right)
$$

where $\Phi_{u}$ is the ultimate curvature.

Many empirical equations are available for calculation of the equivalent plastic hinge length $\left(L_{p}\right)$. For example, Equation 11 is recommended from Priestley et al. (2007) for RC cantilever walls.

$$
L_{p}=k H_{e}+0.1 L_{w}+L_{y p}
$$

where $k$ is a constant reflecting the distribution of plasticity dependent on the ratio of the ultimate strength to yield strength of the reinforcing steel $\left(k=0.2\left(f_{u} / f_{y}-1\right) \leq 0.08\right)$ and $L_{y p}$ is the strain penetration length defined in Priestley et al. (2007) with Equation 12. 


$$
L_{y p}=0.022 f_{y e} d_{b l}
$$

where $f_{y e}$ is the expected yield stress of the steel $\left(1.1 f_{y}\right)$.

More recently, Equation 13 was specifically derived from analytical and experimental results of RC C-shaped walls from (Constantin, 2016).

$$
L_{p}=\left[0.05 H_{e}+0.05 L_{w}\left(\frac{\tau}{0.17 \sqrt{f_{c}^{\prime}}}\right)\right](1+4 A L R)
$$

where $A L R$ is the axial load ratio and $\tau$ is the average shear stress parameter, which can be calculated from a sectional analysis ("moment-curvature" analysis) or can be estimated by dividing the base shear $\left(V_{b}\right)$ of the wall by the effective area $\left(A_{e f f}\right)$ of the section. The $A L R$ is calculated as $P / f_{\text {cmi }} A_{g}$, where $P$ is the axial force on the wall, $f_{c m i}$ is the mean compressive strength of concrete.

However, Equations 11 and 13, as well as many other expressions for estimating $L_{p}$ (Bohl \& Adebar, 2011; Kazaz, 2013; Paulay, 1986; Priestley \& Park, 1984; Thomsen \& Wallace, 2004; Wallace \& Moehle, 1992), have been derived primarily from analytical and experimental results for RC elements that are not representative of lightly reinforced and unconfined concrete walls in regions of low-tomoderate seismicity. It was shown in Hoult et al. (2017) and Hoult et al. (2018) that these commonly used expressions provide a large scatter of results in comparison to the $L_{p}$ derived from numerical analyses for lightly reinforced rectangular and C-shaped walls respectively. Subsequently, an expression was derived to predict the $L_{p}$ for lightly reinforced and unconfined rectangular walls with Equation 14. Importantly, this expression was only recommended to be used for RC walls that had a sufficient amount of longitudinal reinforcement to allow secondary cracking. Thus, if a wall has a longitudinal reinforcement ratio less than the minimum required to initiate secondary cracking $\left(\rho_{w v}<\right.$ $\rho_{\text {wv.min }}$ ), a $L_{p}$ of $100 \mathrm{~mm}$ was recommended for design purposes; a slightly less conservative $L_{p}$ of 150 $\mathrm{mm}$ will be used here for assessment purposes. It should be noted that the $L_{p}$ of $150 \mathrm{~mm}$, corresponding to the strain penetration length $\left(L_{y p}\right)$, is close to the value of that calculated with Equation 12 (assuming the $d_{b l}$ is $12 \mathrm{~mm}$ ). Furthermore, the value of $150 \mathrm{~mm}$ is approximate to the mean of the $L_{p}$ values determined from the results of all of the rectangular and C-shaped walls with a $\rho_{w v}$ less than $\rho_{w v \cdot \min }$ analysed in VecTor3 using the Equivalent Plastic Hinge Length method (Hoult et 
261 15). More information about the derivation and limitations of the $L_{p}$ expression for lightly reinforced 262 rectangular concrete walls can be found in Hoult et al. (2017).

$$
\begin{aligned}
& L_{p}=\left(0.1 L_{w}+0.075 H_{e}\right)(1-6 A L R) \leq 0.5 L_{w} \\
& \rho_{w v . \min }=\frac{\left(t_{w}-n_{t} d_{b t}\right) f_{c t . f l}}{f_{u} t}
\end{aligned}
$$

263 where $t_{w}$ is the thickness of the wall, $n_{t}$ is the number of grids of transverse reinforcing bars, $d_{b t}$ is the 264 diameter of the transverse reinforcing bars and $f_{u}$ is the ultimate tensile strength of the reinforcing 265 steel. The $f_{\text {ct. } f l}$ can be approximated using the expressions given in fib (2012).

266 Expressions for predicting the $L_{p}$ of lightly reinforced and unconfined C-shaped walls were also 267 derived for the 3 different modes of bending (about the major axis $\left[L_{p \text { major }}\right]$ and about the minor axis 268 with web in compression $\left[L_{p . \text { minor.WiC }}\right]$ and web in tension $\left.\left[L_{p . m i n o r . W i T}\right]\right)$, given in Equations 16,17 and 26918 respectively. It should be noted that these expressions (Equations 16 to 18 ) should only be used 270 for walls that have a sufficient amount of longitudinal reinforcement for secondary cracking; if a C271 shaped wall has a $\rho_{w v}$ less than $\rho_{w v \cdot \min }$ (Equation 15), then a $L_{p}$ of $150 \mathrm{~mm}$ is used here for assessment 272 purposes (as discussed above). More information about the derivation and limitations of the $L_{p}$ 273 expressions for lightly reinforced C-shaped concrete walls can be found in Hoult et al. (2018).

$$
L_{\text {p.major }}=\left(0.1 L_{\text {web }}-0.013 H_{e}\right)(1-13 A L R)\left(7 e^{-0.8 v}\right) \leq 0.5 L_{w e b}
$$

where $L_{\text {web }}$ is the length of the web of the C-shaped wall (Figure 4) and $v$ is the average normalised shear stress. The $v$ parameter is calculated as $\tau / 0.17 \sqrt{f_{c m i}}$, where the $0.17 \sqrt{f_{c m i}}$ term is taken from ACI-11 (ACI, 2011) for the shear stress capacity at diagonal cracking, which is also used in AS 3600:2009 (Standards Australia, 2009) for the calculation of the minimum shear strength of a wall

278 (without consideration of the shear reinforcement).

$$
L_{\text {p.minor.WiC }}=\left(0.5 L_{\text {flange }}-0.015 H_{e}\right)(1-3 A L R)\left(1.6 e^{-0.1 v}\right) \leq L_{\text {flange }}
$$




$$
L_{\text {p.minor.WiT }}=\left(1.0 L_{\text {flange }}-0.073 H_{e}\right)(1-8 A L R)\left(2.5 e^{-2.1 v}\right) \leq 0.5 L_{\text {flange }}
$$

\subsection{Shear Displacement}

281 As previously mentioned in Section 2.1, a common assumption in a plastic hinge analyses for

282 rectangular $\mathrm{RC}$ wall sections with large $A_{r}$ is to neglect the shear and slip displacements (Almeida $e t$

$283 a l ., 2016)$. For example, this assumption appeared to be valid for the three experimental lightly

284 reinforced rectangular concrete walls tested by Albidah (2016) and Altheeb (2016). However, for

285 non-rectangular wall sections (e.g. C-shaped), shear deformations can represent a larger portion of the

286 total displacement capacity of the wall in comparison to that for rectangular walls. For instance,

287 Beyer (2007) found that the shear-to-flexure $\left(\Delta_{s} / \Delta_{f}\right)$ ratios of the two experimentally tested C-shaped

288 walls ranged from approximately $8 \%$ to $38 \%$, depending on the direction of loading. Moreover,

289 recent experimental testing on two other C-shaped walls from Constantin (2016) found similar values

290 for the same directions of loading, with $\Delta_{s} / \Delta_{f}$ values ranging from $16 \%$ to $33 \%$. Given the potential

291 for shear deformations to make a large contribution to the overall displacement capacity of RC C-

292 shaped walls, it is important to incorporate a shear deformation model into the PHA for these types of 293 walls.

294 Over the past decade or so, several models have been recommended for use in predicting the shear

295 displacement of RC walls, and these can be incorporated into a PHA (Beyer et al., 2011; Hannewald,

296 2013; Hines et al., 2004; Priestley et al., 2007). The simplified method for incorporating the shear

297 deformations $\left(\Delta_{s}\right)$ in a PHA for RC walls is to compare the shear contribution to the overall flexural

298 deformation $\left(\Delta_{f}\right)$. This is because the shear-to-flexure ratio $\left(\Delta_{s} / \Delta_{f}\right)$ has previously been found to be

299 relatively constant throughout the inelastic range (Beyer et al., 2011; Hines et al., 2004).

300 The $\Delta_{s} / \Delta_{f}$ deformation model proposed by Beyer et al. (2011) is expressed in the form of Equation

301 19. This expression (Equation 19) assumes that the shear-to-flexure ratio is constant throughout the

302 inelastic range and that the shear deformations only occur in the equivalent plastic hinge region.

$\frac{\Delta_{s}}{\Delta_{f}}=1.5\left(\frac{\varepsilon_{m}}{\Phi_{u} \tan \theta_{c}}\right)\left(\frac{1}{H_{e}}\right)$ 
where $\varepsilon_{m}$ is the mean axial strain of the RC section (which can be estimated from a moment-curvature 304 analysis) and $\theta_{c}$ is the crack angle.

305 The crack angle $\left(\theta_{c}\right)$ has traditionally been taken as $45^{\circ}$ (Krolicki et al., 2011), a value which is also 306 used for design purposes (Beyer et al., 2011). However, recent research has indicated that there is 307 some variability in the cracking angle, which can range from $25^{\circ}$ to $65^{\circ}$ (Krolicki et al., 2011). 308 Moreover, Priestley et al. (1996) recommended an average cracking angle of $30^{\circ}$ to be used for the 309 assessment of existing structures.

\section{Finite element modelling results}

311 An extensive number of finite element modelling analyses were originally conducted in Hoult et al.

312 (2017) and Hoult et al. (2018) for lightly reinforced and unconfined rectangular and C-shaped walls

313 respectively. The strain distribution results from the numerical analyses were initially used to

314 calculate the equivalent plastic hinge length for a range of walls and different parameters with values

315 that would be prevalent in the low-to-moderate seismic region of Australia. The force-displacement

316 relationships from these same numerical analyses are used in this research to investigate that

317 displacement capacity, with comparisons being made to the estimates from PHA. The next section

318 briefly discusses how the finite element modelling programs were validated, which is followed by

319 sections that summarise the different wall parameters that were used in the numerical analyses. For

320 the sake of brevity, the reader is referred to Hoult et al. (2017) and Hoult et al. (2018) for more

321 information with regards to the finite element modelling programs used, model and mesh setup, as

322 well as the subsequent material models used (and validation of such models).

\subsection{Validation of VecTor}

324 VecTor2 (Wong et al., 2013) and VecTor3 (ElMohandes \& Vecchio, 2013) are state-of-the-art 325 nonlinear finite element modelling programs used for RC 2-dimensional and 3-dimensional solids 326 (respectively) that use the Disturbed Stress Field Model (DSFM) (Vecchio et al., 2000). Information 327 about the program and some improvements of the predictions for the behaviour of RC elements can 328 be found in Wong et al. (2013) and ElMohandes (2013). VecTor2 has been used in a variety of past 
research for modelling RC walls (Beyer, 2007; Bohl \& Adebar, 2011; Dai, 2011; Ghorbani-Renani et

330 al., 2009; Lu et al., 2014; Luu et al., 2013; Sritharan et al., 2014). To the authors' knowledge

331 VecTor3 has only been used for comparison with one past experimental study on RC walls (Peña,

332 2001). The results from Peña (2001) on a $\mathrm{H}$-shaped wall using VecTor3 compared well to the results

333 given by VecTor2, as the wall was symmetrical and could be analysed by both programs.

334 A range of material models have been incorporated in VecTor2 and VecTor3 to represent modelling

335 of the concrete and steel materials. These models were used for the finite element modelling analyses

336 conducted in Hoult et al. (2017) and Hoult et al. (2018) for lightly reinforced and unconfined

337 rectangular and C-shaped walls respectively. These models are summarised in Table 2, where the

338 reader is directed to Hoult et al. (2017) and ElMohandes and Vecchio (2013) for more information on

339 the selected models.

Table 2 Material models used in VecTor2 and VecTor3

\begin{tabular}{cc}
\hline Constitutive Behavior & Model \\
\hline Compression Pre-Peak & Popovics NSC $/$ Popovics HSC ${ }^{2}$ \\
Compression Post-Peak & Popovics NSC $/$ Popovics HSC ${ }^{2}$ \\
Compression Softening & Vecchio 1992-B (e1/e0-Form) \\
Tension Stiffening & Modified Bentz 2003 \\
Tension Softening & Bilinear \\
FRC Tension & Not Considered \\
Confined Strength & Kupfer/Richter \\
Dilation & Variable - Kupfer \\
Cracking Criterion & CEB-FIP Model (Kupfer et al., 1973) \\
Crack Stress Calc & Basic (DSFM/MCFT) \\
Crack Width Check & Aggregate 2.5mm Max Crack Width (Deafult) \\
Crack Slip Calc & Walraven (Monotonic) \\
Creep and Relaxation & Not Available \\
Hysteretic Response & Palermo 2002 (with Decay) \\
\hline
\end{tabular}

${ }^{1}$ Normal Strength Concrete (NSC) $<45 \mathrm{MPa}$

${ }^{2}$ High Strength Concrete (HSC) $\geq 45 \mathrm{MPa}$

342 VecTor2 was shown in Hoult et al. (2017) to provide reasonably good results in comparison to the

343 relevant experimental data from rectangular wall specimens R1 from Oesterle et al. (1976) and C1

344 from Lu et al. (2015), including the force-displacement relationship (monotonic and reverse cyclic), 
cracking distribution and strain/curvature distribution up the height of the wall. Furthermore, the

experimental results from specimens Wall1 and Wall2 from Altheeb (2016) were also used in Hoult

347 (2017) to determine the applicability of the material models (Table 2) for VecTor2. Importantly,

348 Wall1 and Wall2 were both lightly reinforced and unconfined rectangular walls detailed to current

349 Australian practice (Altheeb, 2016), with Wall1 forming a single-crack at the base of the wall during

350 testing. The force-displacement results from VecTor2 for Wall1 and Wall2 (and for monotonic

351 loading) is given in Figure 5.

a) Average Drift

$-4.50 \%-3.00 \%-1.50 \% 0.00 \% 1.50 \% 3.00 \% 4.50 \%$

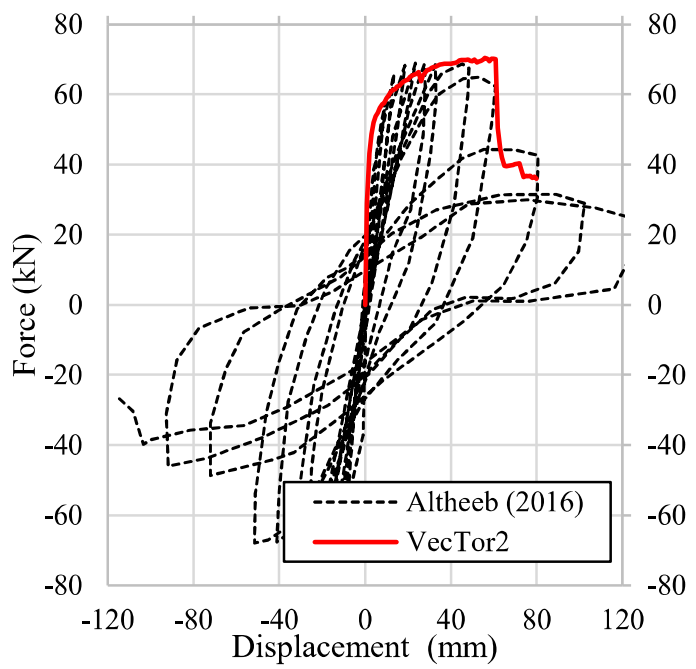

b) Average Drift

b) $-4.50 \%-3.00 \%-1.50 \% 0.00 \% 1.50 \% 3.00 \% 4.50 \%$

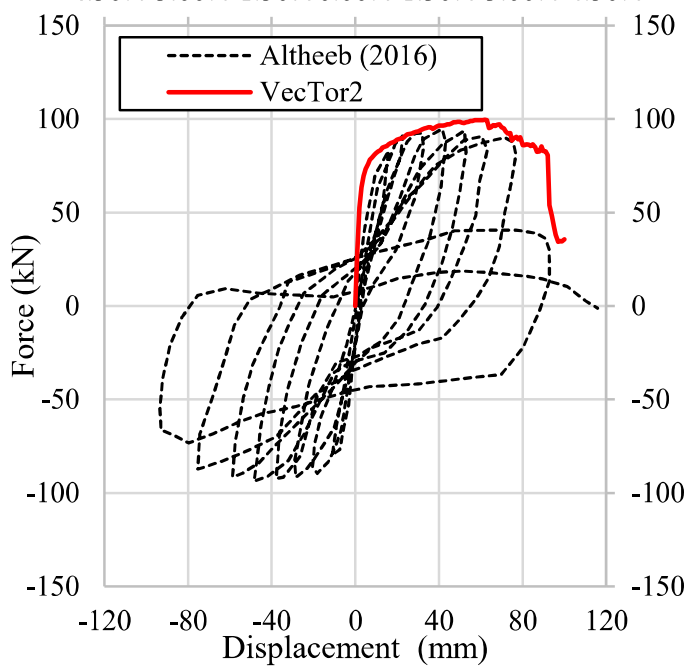

Figure 5 VecTor2 results for (a) Wall1 and (b) Wall2 from Altheeb (2016)

353 VecTor3 was shown to provide reasonably good results in Hoult et al. (2018) in comparison to the

354 relevant experimental data for C-shaped wall specimens TUA from Beyer et al. (2008b) and S02 from

355 Menegon et al. (2017), including the force-displacement relationship (monotonic and reverse cyclic),

356 cracking distribution and strain/curvature distribution up the height of the wall. Importantly, wall

357 specimen S02 from Menegon et al. (2017) was an unconfined C-shaped core wall (box-shaped

358 building core with door opening) that was 'designed to best represent current building practices in

359 Australia'. The force-displacement relationship determined from VecTor3 for wall specimen S02

360 (and for both reverse cyclic and monotonic loading) is shown in Figure 6, where the experimental

361 relationship from Menegon et al. (2017) is superimposed in the figure. It should be noted that the

362 VecTor3 monotonic analysis for the modelled S02 wall specimen (results shown in Figure 6) was 
pushed past what the authors of this research have defined as failure, which corresponds to the

364 limiting strain values for "Collapse Prevention" (discussed in Section 2). The circle symbol in Figure

3656 indicates when the unconfined concrete strain of -0.003 was reached in the VecTor3 monotonic

366 analysis. This ultimate displacement corresponds to an average drift of $1.57 \%$, which is similar to the

$3671.5 \%$ average drift reached experimentally in Menegon et al. (2017) before 'lateral load failure'

368 occurs. The experimental specimen S02 was found to fail with degradation of the concrete 'due to a

369 combination of tensile fracturing, unzipping of the lap splice and bond failure between the concrete

370 and reinforcement in the previous reversed load cycle' (Menegon et al., 2017). The VecTor3 model

371 of S02 is unable to capture this degradation, as the lap splice and discontinuity of longitudinal

372 reinforcement up the height of the wall were not modelled in VecTor3 (Hoult et al., 2018) and

373 smeared longitudinal (and transverse) reinforcement were used to model the bars (where bond

374 degradation cannot be modelled). However, it is shown that an unconfined compression strain of -

3750.003 does a reasonable job of estimating failure (or onset of failure) for this wall specimen.

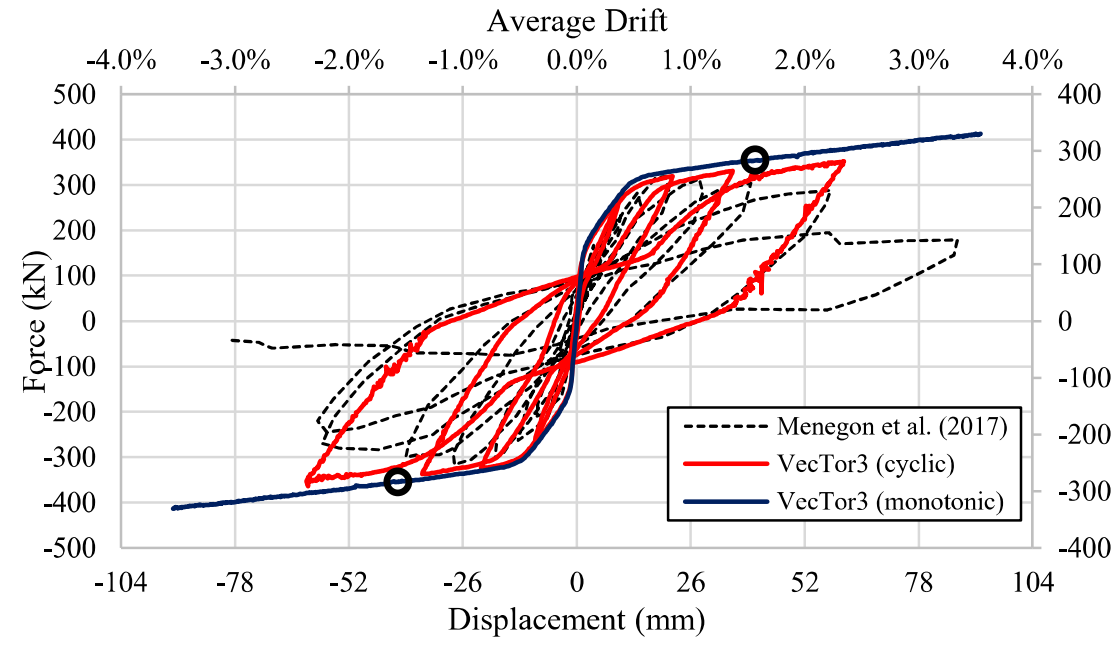

Figure 6 Force-displacement results from VecTor3 for wall specimen S02

\subsection{Rectangular walls}

VecTor2 (Wong et al., 2013) was used in Hoult et al. (2017) to analyse a total of 378 lightly

reinforced and unconfined rectangular concrete walls with varying parameters. The range of different parameters are discussed below and summarised in Table 3. 
The effective height $\left(H_{e}\right)$ is estimated to be $0.7 H_{n}$ as recommended by Priestley et al. (2007) and all of

383 the walls' aspect ratios $\left(A_{r}\right)$ are equal to or greater than 2 (governed by flexure). The $A L R$ s have been

384 chosen to represent the majority of the building stock in low-to-moderate seismic regions, where

$385 A L R$ s of less than $5 \%$ are common in walls with low vertical reinforcement (Henry, 2013). Moreover,

386 the RC walls investigated by Albidah et al. (2013) for low-to-moderate seismic regions indicated that

387 most of the walls had $A L R$ s less than 5\%, and the highest $A L R$ did not exceed $10 \%$. The minimum

388 transverse reinforcement ratio of 0.25\% from AS 3600:2009 (Standards Australia, 2009) is used for

389 all of the walls. The minimum longitudinal reinforcement ratio $\left(\rho_{w v}\right)$ required by AS 3600:2009

390 (Standards Australia, 2009) is $0.15 \%$, while RC walls with $\rho_{w v}$ less than $2.00 \%$ are said to 'represent

391 the great majority of building stock in low-to-moderate seismic regions such as Australia' (Wibowo et

392 al., 2013). As previously discussed in Section 2.1, Adebar and Lorzadeh (2012) believe it is rare for

$393 \mathrm{RC}$ walls to have a $\rho_{w v}$ higher than $1.00 \%$. Therefore, the $\rho_{w v}$ values used were $0.15 \%, 0.30 \%, 0.45 \%$,

$3940.60 \%, 0.75 \%, 0.90 \%$ and $1.00 \%$. The longitudinal reinforcement is distributed evenly throughout the

395 wall, which is commonly practice in low-to-moderate seismic regions (Hoult et al., 2017). The two

$396 f_{c m i}$ values of the walls considered in this study were $40 \mathrm{MPa}$ and $60 \mathrm{MPa}$, which are realistic values

397 for walls designed originally with a characteristic compressive strength $\left(f_{c}^{\prime \prime}\right)$ of $32 \mathrm{MPa}$ and $40 \mathrm{MPa}$,

398 given that the target strength would have been higher than this and that the concrete strength will

399 increase with time. The $f_{c m i}$ values adopted correspond to increased strength factor $\left(\kappa=f_{c m i} / f_{c}^{\prime}\right)$

400 values of 1.25 and 1.50 respectively; these are values representative of concrete that has aged over

401 several years as indicated in Moehle (2015). Mean values of the material properties for the

402 reinforcing steel were adopted from Menegon et al. (2015) for D500N bars which conform to

403 AS/NZS 4671 (Standards Australia/New Zealand, 2001). The $f_{y}$ used was $551 \mathrm{MPa}$ with a Young's

404 Modulus $(E)$ of $200,000 \mathrm{MPa}$ and ultimate-to-yield stress ratio $\left(f_{u} / f_{y}\right)$ of 1.20 . The ultimate strain for

405 the purpose of the wall assessments was taken as $60 \%$ of the mean value of the uniform elongation

406 strain, i.e. $0.6 \varepsilon_{s u}(0.6 \times 94.6 \mathrm{~mm} / \mathrm{m}=57 \mathrm{~mm} / \mathrm{m})$, based on the recommendations from Priestley et al.

407 (2007) as discussed previously in Section 2.

Table 3 Walls used in VecTor2 with varying parameters

\begin{tabular}{llllllll}
\hline$L_{w}(\mathrm{~m})$ & $t(\mathrm{~m})$ & $A_{r}$ & $H_{e}(\mathrm{~m})$ & $A L R(\%)$ & $f_{c m i}(\mathrm{MPa})$ & $\rho_{w v}(\%)$ & $\rho_{w h}(\%)$ \\
\hline
\end{tabular}




\begin{tabular}{cccccccc}
3 & 0.2 & $2.5,4.1,5.7$ & $7.35,12.25,17.15$ & $1.5,5,10$ & 40,60 & $0.15-1.00$ & 0.25 \\
6 & 0.2 & $2.0,3.3,4.1$ & $12.25,19.60,24.50$ & $1.5,5,10$ & 40,60 & $0.15-1.00$ & 0.25 \\
9 & 0.25 & $2.7,3.8,4.9$ & $24.50,34.30,44.10$ & $1.5,5,10$ & 40,60 & $0.15-1.00$ & 0.25 \\
\hline
\end{tabular}

\subsection{C-shaped walls}

411 VecTor3 (ElMohandes \& Vecchio, 2013) was used in Hoult et al. (2018) to analyse a total of 144

412 lightly reinforced and unconfined $C$-shaped concrete walls with varying parameters. The range of

413 different parameters are discussed below and are summarised in Table 4.

414 Similar to Section 3.2 for the rectangular walls, the $A L R \mathrm{~s}, \rho_{w h}$ and $\rho_{w v}$ values have been chosen to 415 represent common values found in Australia and other low-to-moderate seismic regions. It should 416 also be noted that the longitudinal reinforcement is distributed evenly throughout the C-shaped walls.

417 Furthermore, the same $f_{c m i}$ values used in Section 3.2 for the rectangular walls are used here; the two $418 f_{c m i}$ values considered in this study were $40 \mathrm{MPa}$ and $60 \mathrm{MPa}$. Mean values of the material properties 419 for the reinforcing steel were taken from Menegon et al. (2015) for D500N bars (provided in Section 420 3.2), which conform to AS/NZS 4671:2001 (Standards Australia/New Zealand, 2001). The ultimate strain of the reinforcing steel was taken as $0.6 \varepsilon_{s u}$ based on the recommendations from Priestley et al.

422 (2007) and as discussed previously in Section 3.2.

Table 4 Walls used in VecTor 2 with varying parameters

\begin{tabular}{ccccc}
\hline Wall & $A L R(\%)$ & $f_{c m i}(\mathrm{MPa})$ & $\rho_{w v}(\%)$ & $\rho_{w h}(\%)$ \\
\hline LR & $1.5,5$ & 40,60 & $0.15,0.45,0.70,1.0$ & 0.25 \\
MR & $1.5,5$ & 40,60 & $0.15,0.45,0.70,1.0$ & 0.25 \\
HR & $1.5,5$ & 40,60 & $0.15,0.45,0.70,1.0$ & 0.25 \\
\hline
\end{tabular}

Three different wall sizes have been chosen to represent $\mathrm{C}$-shaped $\mathrm{RC}$ cores enclosing elevators for a 426 low-rise (LR), mid-rise (MR) and high-rise (HR) building. The number of storeys of the LR, MR and HR C-shaped walls was chosen to be 3, 6 and 12 respectively, which are within the range given in FEMA (2010) and Maqsood et al. (2014). Using an inter-storey height of $3500 \mathrm{~mm}$, the effective

429 height $\left(H_{e} \approx 0.7 H_{n}\right)$ is approximately $7.35 \mathrm{~m}, 14.70 \mathrm{~m}$ and $29.40 \mathrm{~m}$ for the LR, MR and HR wall 430 respectively. The number of elevator cars required for the different rise of building determines the 
size of the walls based on the recommendations given in RLB (2014). The LR C-shaped wall was assumed to enclose two elevator cars $(2 \times 500 \mathrm{~kg}, 6$ person), while the MR C-shaped wall was assumed to enclose three cars ( $3 \times 900 \mathrm{~kg}, 12$ person) and the HR C-shaped wall was assumed to enclose four cars $(4 \times 1150 \mathrm{~kg}, 16$ person). The internal dimensions (width $\mathrm{x}$ depth, in $\mathrm{mm})$ of the $500 \mathrm{~kg}, 900 \mathrm{~kg}$ and $1150 \mathrm{~kg}$ elevator cars are $1000 \times 1300,1400 \times 1500$ and $1500 \times 1800$ respectively. Therefore, the resulting lengths of the web $\left(L_{w e b}\right)$ and flange $\left(L_{\text {flange }}\right)$ that were required for the three different walls are given in Table 5. After some discussions with P. McBean (personal communication, February 26, 2016), a consulting engineer and Joint Managing Director of Wallbridge \& Gilbert, 200mm thick walls and a length of $600 \mathrm{~mm}$ (approximately $2 \mathrm{ft}$ ) for the returns $\left(L_{\text {return }}\right)$ were taken as values that reflect current and past practice in Australia. The thickness $\left(t_{w}\right)$ of the HR C-shaped wall was increased to $250 \mathrm{~mm}$, as shown in Table 5. The $A_{r}$ values of the C-shaped walls, which are all greater than 2.0, are different depending on the direction of loading; for bending about the major axis, the $A_{r}$

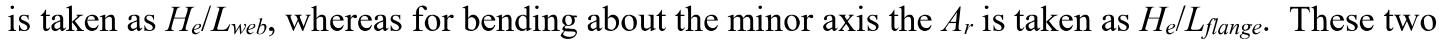
different $A_{r}$ values for each of the walls are given in Table 5.

Table 5 Dimensions of the C-shaped walls

\begin{tabular}{ccccccc}
\hline Wall & $t_{w}(\mathrm{~mm})$ & $L_{\text {web }}(\mathrm{mm})$ & $L_{\text {flange }}(\mathrm{mm})$ & $L_{\text {return }}(\mathrm{mm})$ & $A_{r}$ & $H_{e}(\mathrm{~m})$ \\
\hline LR & 200 & 3600 & 2000 & 600 & $2.1^{\mathrm{a}}, 3.7^{\mathrm{b}}$ & 7.35 \\
MR & 200 & 6200 & 2200 & 600 & $2.4^{\mathrm{a}}, 6.7^{\mathrm{b}}$ & 14.70 \\
HR & 250 & 8500 & 2500 & 600 & $3.4^{\mathrm{a}}, 11.7^{\mathrm{b}}$ & 29.30 \\
\hline
\end{tabular}

${ }^{\mathrm{a}}$ For bending about the major axis

${ }^{b}$ For bending about the minor axes

\section{Displacement capacity results}

The following sections discuss the finite element modelling results, in terms of the displacement capacities achieved, from the rectangular and $\mathrm{C}$-shaped wall analyses. The curvature and displacement estimates from the numerical results are compared to the estimates made with PHA. Recommendations are ultimately given to improve the PHA accuracy for these types of walls.

\subsection{Displacement capacity of rectangular walls}

\subsubsection{Yield Curvature}


454 As discussed previously in Section 2.1, a value of 2.0 is commonly used for $K_{l}$ when estimating $\Phi_{y}$

455 for rectangular RC walls using Equation 9. A $K_{l}$ value of 2.0 was found to overpredict the yield

456 curvature in comparison to experimental observations of six rectangular structural $\mathrm{RC}$ walls tested on

457 a shaker table by Lestuzzi and Bachmann (2007). Lestuzzi and Bachmann (2007) found that the poor

458 correlation is the result of the properties of reinforcing steel that is outside the limitations of the

459 equation proposed by Priestley and Kowalski (1998), as discussed in Section 2.1. Interestingly, the

460 reinforcing steel used in these experimental RC wall specimens had mechanical properties similar to

461 the D500N bars used for this research investigation.

462 Using the minimum of the sum of the squares for the results of the 378 rectangular walls analysed in

463 VecTor2, it was found that a $K_{l}$ value of 1.7 correlated well to the VecTor2 results for the nominal

464 yield curvature $\left(\Phi_{y}\right)$ when using Equation 9. The resulting value of 1.7 was within the values (of $K_{l}$ )

465 adopted by Lestuzzi and Bachmann (2007) of 1.75 and 1.56, depending on whether the experimental

466 rectangular wall specimens that were tested had light or heavy amounts of longitudinal reinforcement

467 concentrated (lumped) at the ends of the wall. The yield curvature estimates using $K_{l}$ values of 1.7

468 and 2.0 are illustrated in Figure 7; although the same $R^{2}$ value is achieved using either of the $K_{l}$

469 values, it can be observed that the $K_{l}$ value of 2.0 (Figure $7 \mathrm{~b}$ ) primarily overestimates $\Phi_{y}$ in

470 comparison to the VecTor2 data.
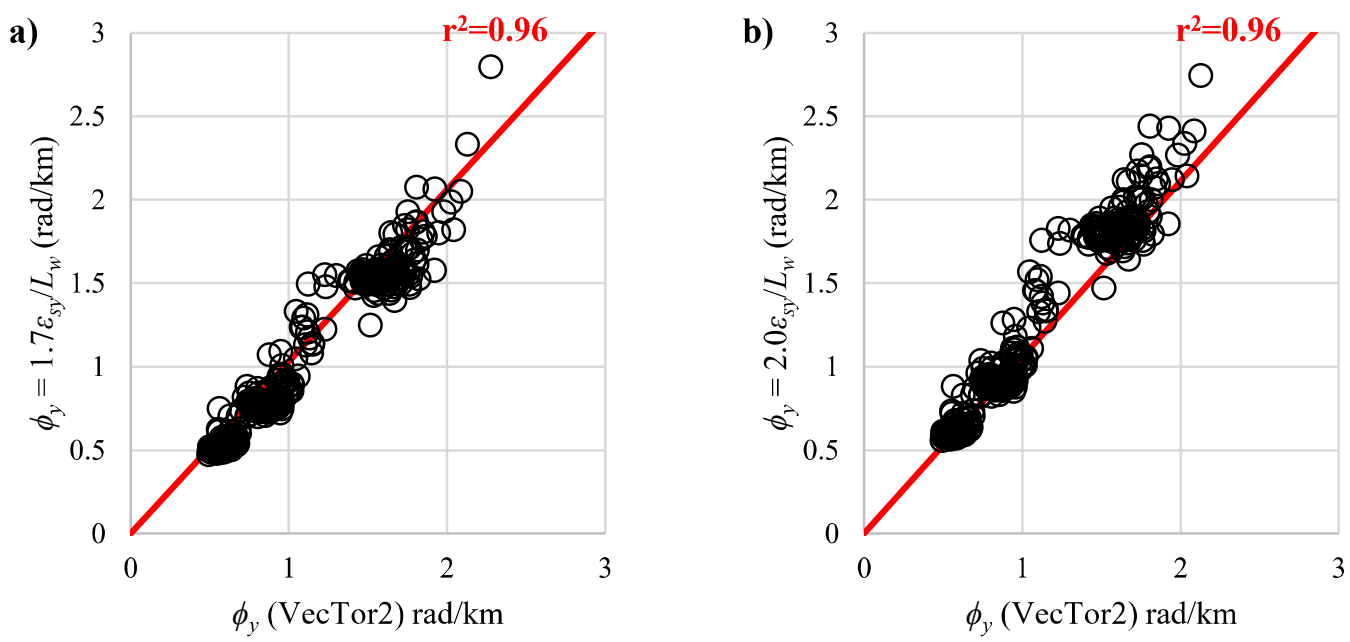

Figure 7 Yield curvature results from VecTor2 compared to estimates using Equation 9 with $K_{l}$ values of (a) 1.7 and (b) 2.0 


\subsubsection{Yield Displacement}

474 The nominal yield displacement $\left(\Delta_{y}\right)$ was found from the VecTor2 results for the lightly reinforced

475 and unconfined rectangular walls. These values were calculated using Equation 1, where the

476 displacement at first yield $\left(\Delta_{y}^{\prime}\right)$ corresponded to the yield strain being reached in the extreme tension

477 fibre region. The results from the numerical analyses showed that $\Delta_{y}$ increased as a function of the $\rho_{w v}$

478 of the walls. For example, the nominal yield displacement values are given as function of the

479 longitudinal reinforcement ratio in Figure 8 for the six-metre rectangular walls (with $f_{c m i}$ of $40 \mathrm{MPa}$ )

480 and three different $A L R$ s. An increasing yield displacement with increasing amounts of the

481 longitudinal reinforcement content is expected, given that a higher $\rho_{w v}$ would induce a larger extent of

482 cracking in the yielding region of the wall; if more cracks form at the base of the wall, the strain is

483 more evenly distributed up the wall height, allowing higher displacement capacities to be achieved.

484 Little variance can be observed in Figure 8 for the $\Delta_{y}$ achieved by the walls with the different $A L R$,

485 particularly for the walls with a higher $\rho_{w v}$ (or once secondary cracking is achieved). Based on the

486 work in Hoult et al. (2017) and Equation 15, the minimum longitudinal reinforcement ratio $\left(\rho_{\text {wv.min }}\right)$

487 required to initiate secondary cracking is approximately $0.50 \%$ and $0.65 \%$ for the $40 \mathrm{MPa}$ and 60

$488 \mathrm{MPa}$ RC walls. These estimated values of $\rho_{w v \cdot \min }$ were shown to correspond well to the cracking and

489 strain distributions investigated using the same numerical results in Hoult et al. (2017). As reflected

490 in Figure 8, a higher $\Delta_{y}$ is achieved when secondary cracking occurs in comparison to the walls with

491 insufficient longitudinal reinforcement. In the latter case, the wall exhibits a single, primary crack,

492 where the yield and plastic strains are concentrated over a small height of the wall, and hence a lower

493 nominal yield displacement capacity is achieved for these walls. 


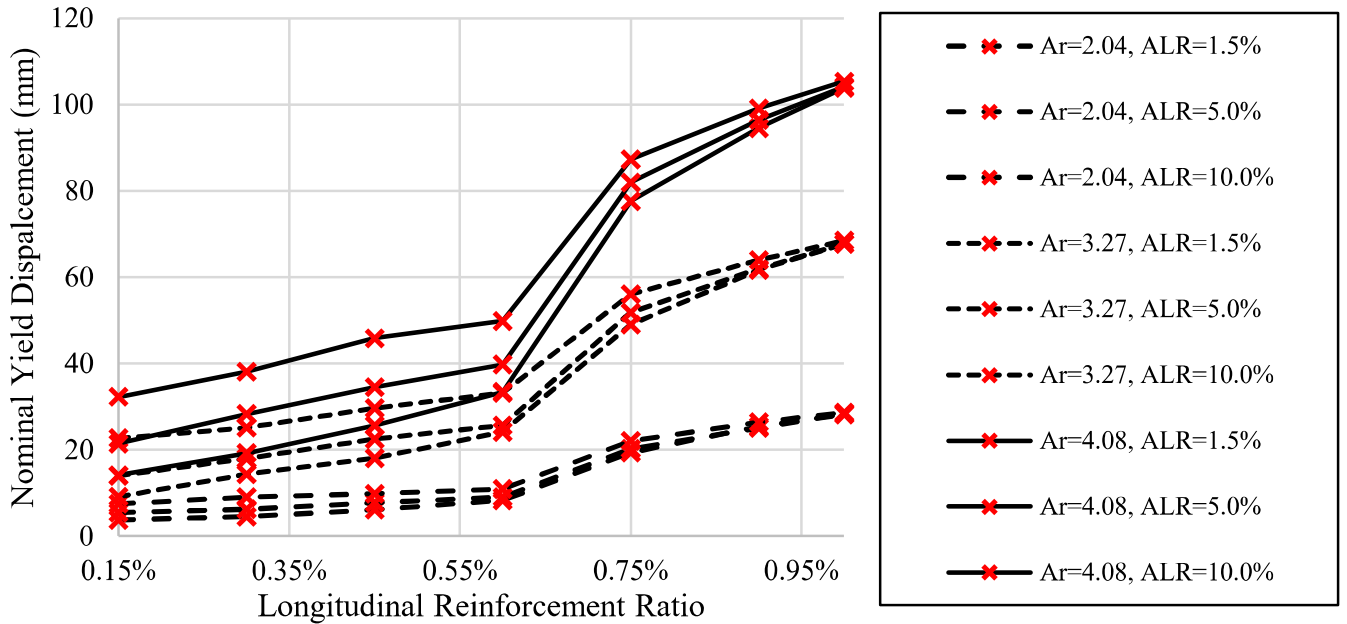

Figure 8 Nominal yield displacement as a function of longitudinal reinforcement for the 6 metre (40 MPa) rectangular walls

Interestingly, the PHA approach recommended by Priestley et al. (2007) for calculating $\Delta_{y}$ (Equation

2) is independent on the flexural strength of the wall and is therefore constant throughout the range of $\rho_{w v}$ used for a given cross-section of wall. This is shown in Figure 9, where the $\Delta_{y}$ estimates using Equation 2 from Priestley et al. (2007) are superimposed with the $\Delta_{y}$ results from VecTor2 for the 6 metre (40 MPa, $5 \% A L R)$ rectangular walls of varying aspect ratio $\left(A_{r}\right)$. It should be noted that the nominal yield curvature $\left(\Phi_{y}\right)$ in Equation 2 has been calculated using Equation 9, where a value of 1.7 was used for $K_{l}$, due to the findings in Section 4.1.1, and a value of 0.0027 for $\varepsilon_{s y}$. The estimated $\Delta_{y}$, using the expression from Priestley et al. (2007), overpredicts the $\Delta_{y}$ in comparison to the numerical results throughout the $\rho_{w v}$ range, even with the reduced value of 1.7 [from 2.0 recommended in Priestley et al. (2007)] for $K_{l}$ for lightly reinforced walls. This conforms with the supposition from Beyer (2007) discussed in Section 2.1, where it was suggested that the linear curvature profile approach [from Priestley et al. (2007)] will overestimate the nominal yield displacement capacity. To illustrate this further, Figure 10 gives the curvature profile at yield for the 6 metre walls ( $40 \mathrm{MPa}$, $A L R$ of $5 \%$ and an $A_{r}$ of 3.27) with varying $\rho_{w v}$. Superimposed on this figure is the linear curvature profile, which is one of the assumptions used to derive Equation 2 from Priestley et al. (2007). It should be noted that the height of the wall in Figure 10 has been normalised to the height of the cantilever wall at roof level $\left(H_{n}\right)$ of $28 \mathrm{~m}$. Although it appears that some yielding (and thus, some cracking) has occurred in the majority of the walls (with a sufficient longitudinal reinforcement ratio 
to allow secondary cracking) and in the lower $20-40 \%$ of the wall height (from the base), the actual

516 curvature profiles are far different from the approximate linear curvature profile. Moreover, the

517 curvature distribution becomes more linear as the longitudinal reinforcement ratio increases, which

518 explains the trend illustrated in Figure 8 and Figure 9.

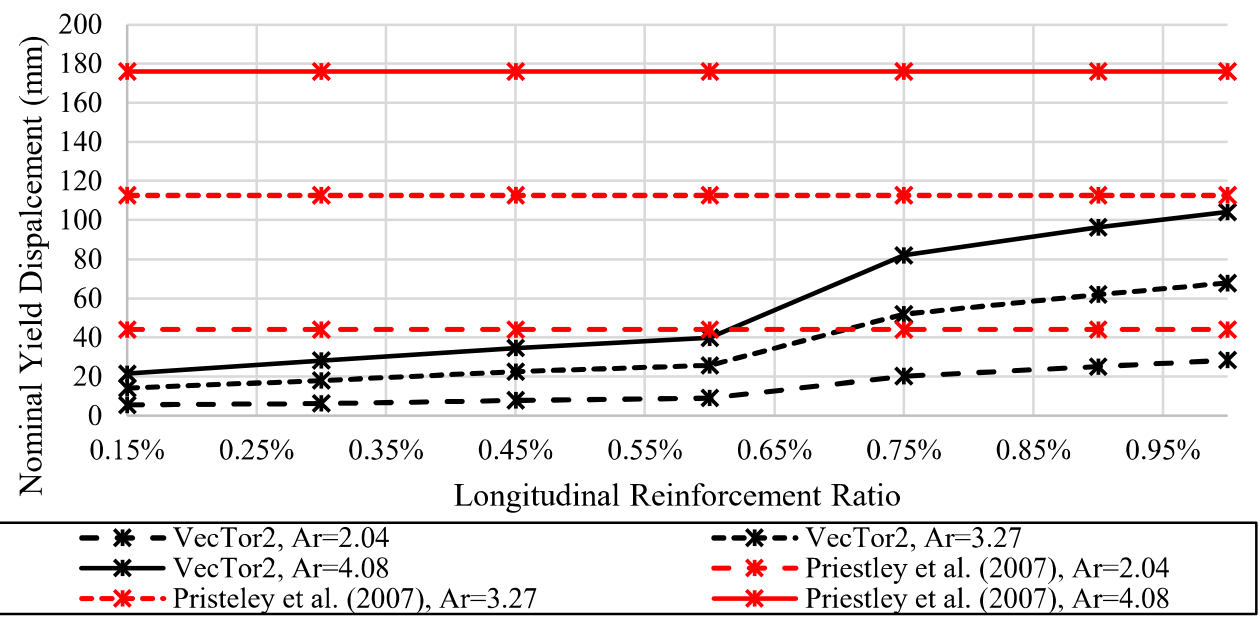

Figure 9 Nominal yield displacement estimates using the expression by Priestley et al. (2007)

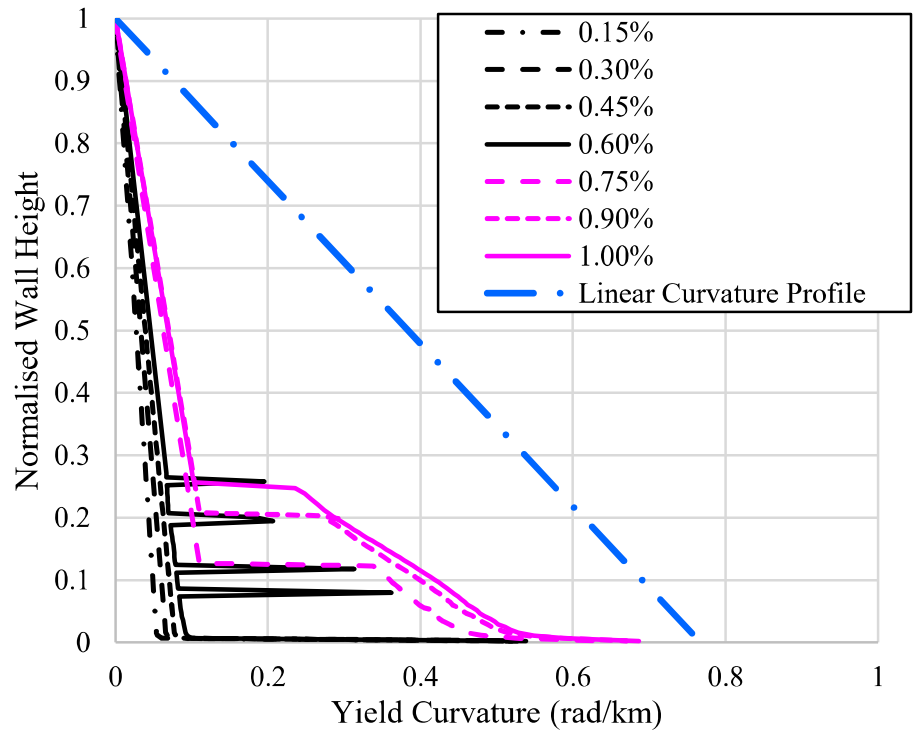

Figure 10 Yield curvature profiles for the 6 metre walls compared to the linear curvature profile

523 In contrast to the PHA approach from Priestley et al. (2007), the method proposed by Beyer (2007)

524 (Equation 3) attempts to determine the height of the wall that is cracked and uncracked. Importantly,

525 Equation 3 is dependent on the ratio of cracked to uncracked flexural wall stiffness $(\alpha)$, which can be 
determined for each RC wall case with the $M_{y}^{\prime}$ and $\Phi_{y}^{\prime}$ values, and the height of the cracked wall $H_{c r}$ (Equation 5), which is determined from the ratio of $M_{c r}$ to $M_{y}^{\prime}$ (Equation 6). Figure 11 gives the $\Delta_{y}$ results as a function of the $\rho_{w v}$ used from VecTor2 for the 6 metre (40 MPa, $5 \% A L R$ ) rectangular walls of varying aspect ratio $\left(A_{r}\right)$, where the $\Delta_{y}$ estimates using Equation 3 are superimposed. It should be noted that $\Phi_{y}$ in Equation 3 has been estimated using a $K_{l}$ value of 1.7 and a value of 0.0027 for $\varepsilon_{s y}$. The majority of the estimated values of $\Delta_{y}$ in Figure 11, using the expression from Beyer (2007) and revised curvature profile from Constantin (2016) (Figure 3), overestimate the displacement in comparison to the values obtained from numerical analyses. There is, however, a noticeable trend that is similar to the results from VecTor2, where the $\Delta_{y}$ increases as a function of the $\rho_{w v}$ used in the wall.

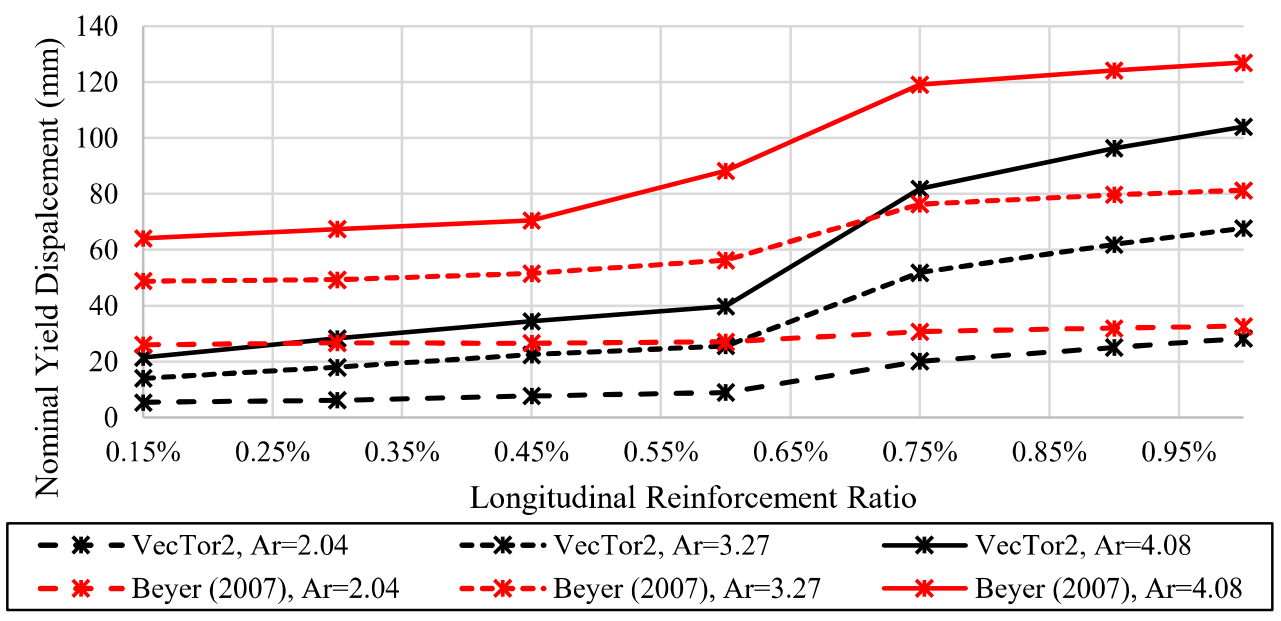

Figure 11 Nominal yield displacement estimates using the expression from Beyer (2007) and Constantin (2016)

539 In order to accurately estimate the $\Delta_{y}$ for lightly reinforced $\left(\rho_{w v} \leq 1.00 \%\right) \mathrm{RC}$ rectangular walls, a

540 parameter $\left(K_{4}\right)$ is introduced here (Equation 20) to modify Equation 3 from Beyer (2007) (termed here

541 as the "modified Beyer" approach). The resulting expression (Equation 21) simply includes the $K_{\Delta}$

542 factor to decrease the estimated $\Delta_{y}$ depending on the $\rho_{w v}$ of the wall; as has been observed, the $\Delta_{y}$

543 increases as a function of $\rho_{w v}$ for lightly reinforced walls. Using the $\Delta_{y}$ values obtained from the

544 VecTor2 analyses for all of the rectangular walls, the minimum of the sum of the squares determined

545 the constants in Equation 20 that resulted in the closest correlation of $\Delta_{y}$ using Equation 21. 
$K_{\Delta}=45 \rho_{w v}+0.22$

$\Delta_{y}=K_{\Delta} \Phi_{y}\left(\frac{k_{c r}}{3} H_{n}^{2}+L_{y p} H_{n}\right)$

546 Figure 12 give the $\Delta_{y}$ results from VecTor2 for the 6 metre (40 MPa, $5 \% A L R$ ) rectangular walls of

547 varying aspect ratio $\left(A_{r}\right)$ and estimates using Equation 21 (modified Beyer approach). It should be

548 noted, as previous, that $\Phi_{y}$ in Equation 21 has been estimated using a $K_{l}$ value of 1.7 and a value of

5490.0027 for $\varepsilon_{s y}$. The modified Beyer approach provides good estimates in comparison to the numerical

550 results for this rectangular wall of varying $A_{r}$ and $\rho_{w v}$. Importantly, the great majority of the estimates

551 in Figure 12 from the modified Beyer approach have given slightly conservative results, rather than an

552 overestimation.

553

554

555

556

557

558

559

560

561

562

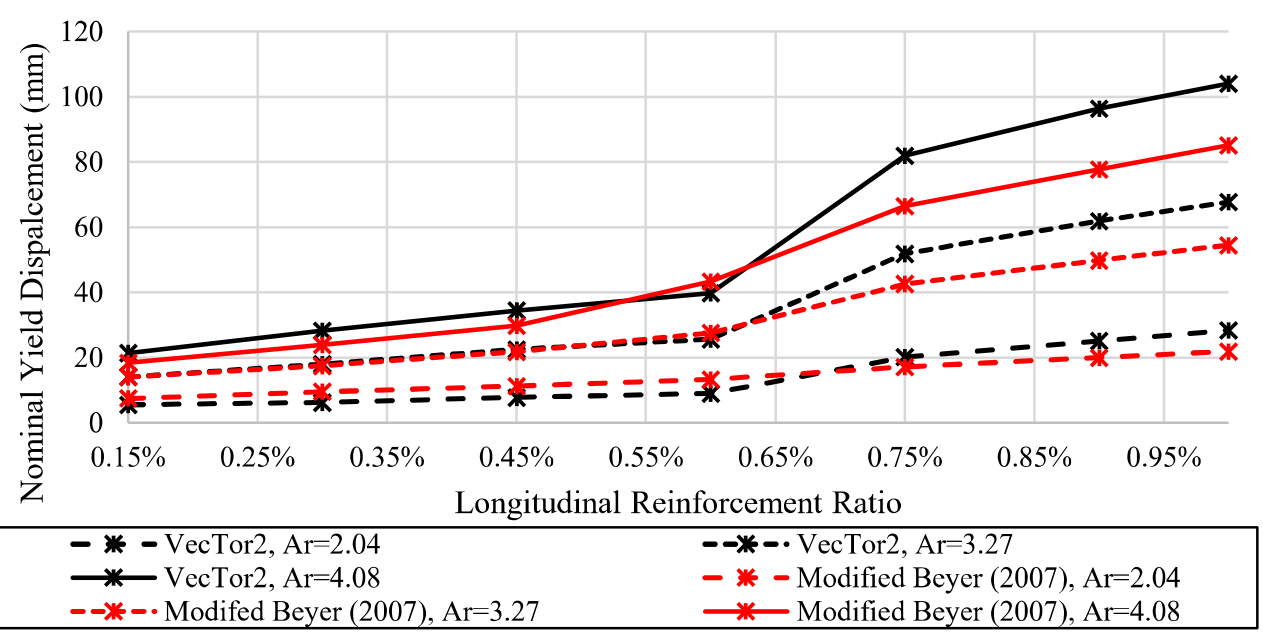

Figure 12 Nominal yield displacement estimates using the modified expression from Beyer (2007) and Constantin (2016)

The estimated $\Delta_{y}$ values, using Equation 21 (modified Beyer approach), in comparison to all of the VecTor2 results are shown to correlate well in Figure 13(c). This is compared to the nominal yield displacement estimates using the expressions from Priestley et al. (2007) and Beyer (2007) in Figure 13(a) and Figure 13(b) respectively, without the $K_{\Delta}$ factor, which over predict the nominal yield displacement compared to the results of all of the rectangular walls analysed in VecTor2. Clearly a better estimate of the $\Delta_{y}$ can be achieved, illustrated with the different $\mathrm{R}^{2}$ correlations in Figure 13 , by including a factor $\left(K_{4}\right)$ for lightly reinforced and rectangular concrete walls. 

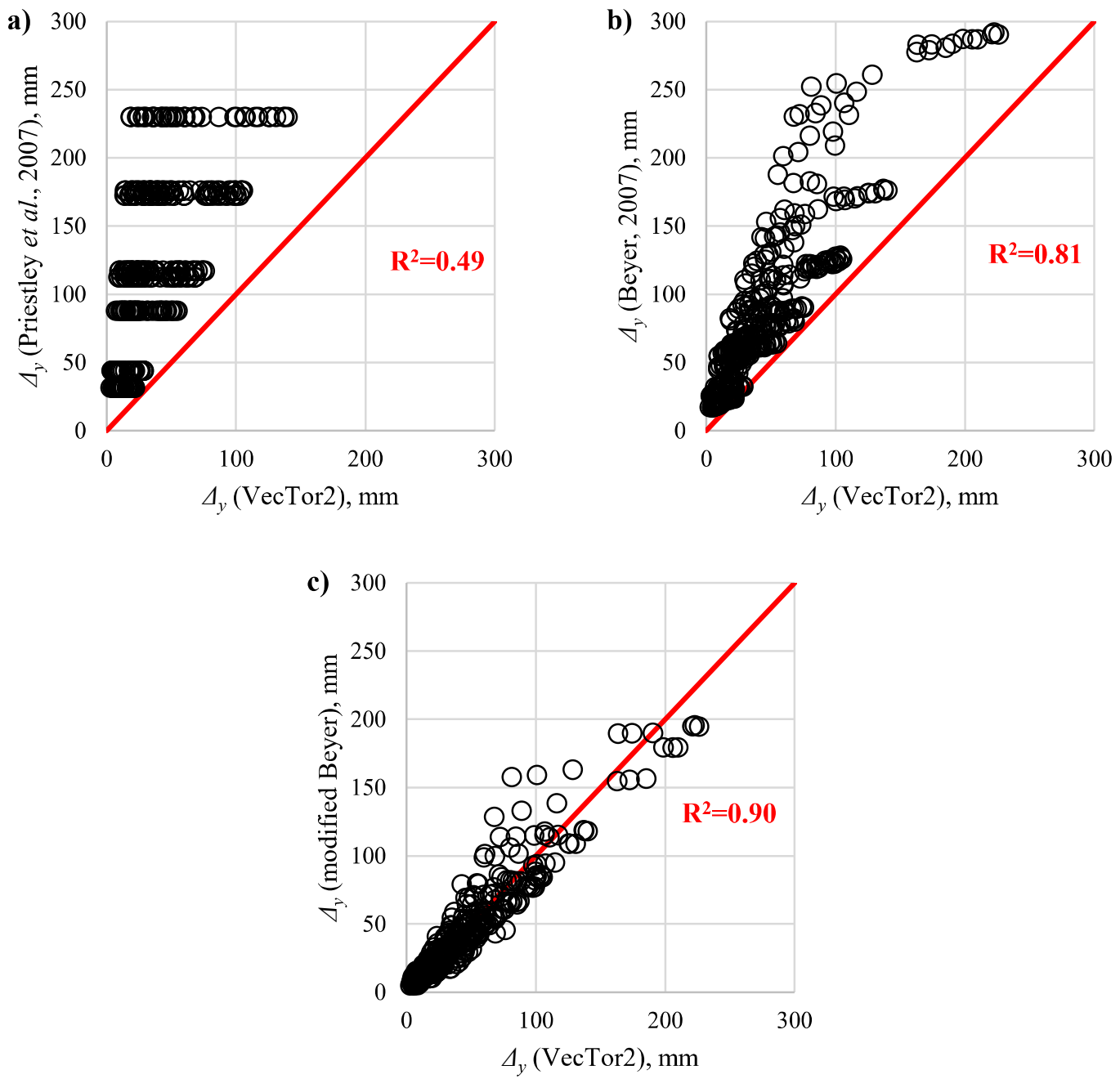

Figure 13 Nominal yield displacement estimates compared to VecTor2 results using expressions from (a) Priestley et al. (2007) (b) Beyer (2007) and (c) modified Beyer approach

\subsubsection{Plastic curvature of single-crack rectangular walls}

As discussed in Section 1, observations from the Christchurch earthquake indicated that some lightly reinforced walls may fail in a non-ductile fashion with a single crack in the plastic hinge zone. In this case, the curvature is concentrated over a small height at the base of the wall. Furthermore, a typical moment-curvature analysis may not be able to predict the ultimate curvature achieved by these types of walls as the performance is governed by strain penetration deformation rather than flexural deformation, where the assumptions inherently built in to a moment-curvature analyses no longer apply. Research by Wibowo et al. (2016) has led to a simplified alternative for the moment and curvature calculations when conducting a sectional analyses for lightly reinforced concrete columns. 
574 However, the expressions recommended by Wibowo et al. (2016) may not be applicable to RC walls

575 since there is typically a greater axial load ratio $(A L R)$ and longitudinal reinforcement ratio $\left(\rho_{w v}\right)$ in

576 lightly reinforced columns in comparison to lightly reinforced walls. However, it is worth noting that

577 the simplified alternative from Wibowo et al. (2016) increases both the yield (or strain) penetration

578 moment and curvature achieved by the column in comparison to the flexural moment and curvature

579 obtained from a sectional analysis.

580 Instead, the proposed plastic curvature estimation here is derived from treating the plastic behaviour

581 due to yield penetration and bond slip at the base as a plastic rotation due to an estimated curvature

582 multiplied by a plastic hinge length. This estimate of the plastic curvature $\left(\Phi_{p}\right)$ of the walls with a

583 single-crack failure is illustrated in Figure 14. The $\Phi_{p}$ can be calculated using Equation 22, which

584 conservatively assumes that no compression region exists over the length of the wall. An ultimate

585 strain value equal to 0.6 of the uniform elongation strain $\left(\varepsilon_{s u}\right)$ for the reinforcing steel is used due to

586 the recommendations by Priestley et al. (2007) for low-cycle fatigue. The yield strain $\left(\varepsilon_{s y}\right)$ value is

587 subtracted from the ultimate strain $\left(0.6 \varepsilon_{s u}\right)$.

$$
\Phi_{p}=\frac{0.6 \varepsilon_{s u}-\varepsilon_{s y}}{L_{w}}
$$

588 In contrast, for walls that achieve secondary cracking, and hence well distributed cracks within the

589 plastic hinge zone, a typical moment-curvature analysis can be used to obtain an estimate of the

590 ultimate curvature $\left(\Phi_{u}\right)$, as it is assumed that the walls' performance will be governed by flexural

591 behaviour. In this case $\Phi_{p}$ can then be calculated by subtracting the estimated nominal yield

592 curvature (e.g. $\left.\Phi_{p}=\Phi_{u}-\Phi_{y}\right)$ 


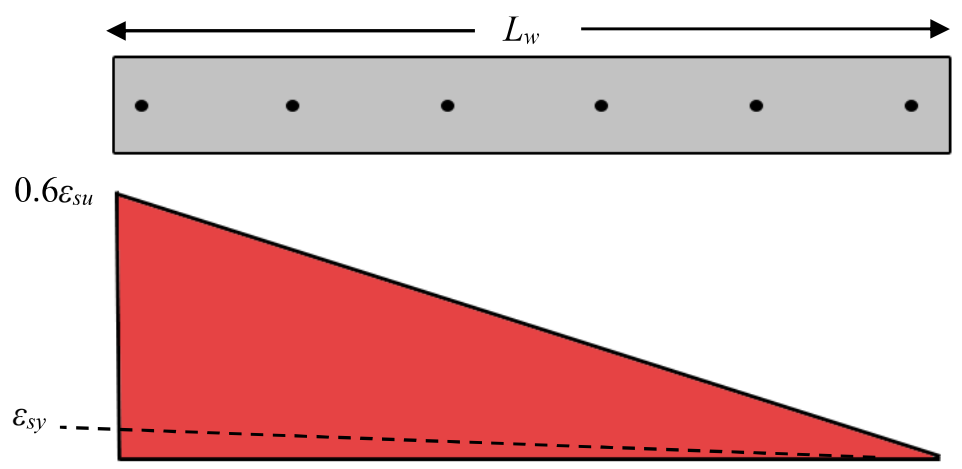

Figure 14 Idealised strain reached at the ultimate state for a single-crack-failure wall

595 Equation 22 is used to calculate the plastic curvature $\left(\Phi_{p}\right)$ for the RC rectangular walls analysed in 596 VecTor2 that were found to form a single, primary crack at the base (correlating with walls having a $\rho_{w v}$ less than $\left.\rho_{w v \cdot m i n}\right)$. The $\Phi_{p}$ values for these walls estimated using Equation 22 are compared to the $\Phi_{p}$ values determined in VecTor3 in Figure 15, where a good fit is achieved.

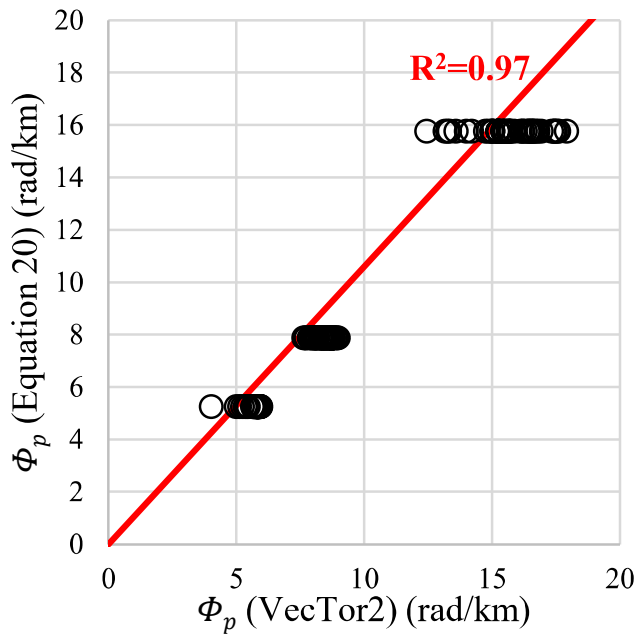

Figure 15 Plastic curvature comparisons for the rectangular walls

\subsubsection{Plastic displacement}

602 Rearranging Equation 10, the $L_{p}$ can be found (using Equation 23) for all of the RC rectangular walls using the $\Delta_{p}$ and plastic curvature $\left(\Phi_{p}=\Phi_{u}-\Phi_{y}\right)$ from the VecTor2 analyses, where the ratio of $\Delta_{s} /$ $\Delta_{f}$ is assumed to be zero. 


$$
L_{p}=\frac{\Delta_{p}}{\Phi_{p} H_{e}}
$$

605 These results are compared to the estimated $L_{p}$ from Hoult et al. (2017) (Equation 14) and Priestley et al. (2007) (Equation 11) in Figure 16. The $L_{p}$ estimates from Hoult et al. (2017), specifically derived

607 for lightly reinforced and rectangular concrete walls, achieves a higher correlation and better fit to the

608 VecTor2 data in comparison to the estimates from Priestley et al. (2007), which gives a large scatter

609 of results. It is noted that Equation 11 from Priestley et al. (2007) can produce good estimates for

610 some walls (shown in Figure 16b), which primarily corresponds to the RC walls that have formed

611 secondary cracking (e.g. where $\rho_{w v} \geq \rho_{w v . m i n}$ ). Importantly, all of the estimated $L_{p}$ values using the

612 expression from Hoult et al. (2017) (Figure 16a) resulted in conservative values in comparison to the

613 VecTor2 data. The good correlation of $L_{p}$ estimates from Hoult et al. (2017) to the VecTor2 data is

614 not all that surprising, given that the same VecTor2 data that is used for comparisons here was used to

615 derive the expression (Equation 14). However, it should be noted that the Equivalent Plastic Hinge

616 Length method was used in Hoult et al. (2017) to derive the $L_{p}$ values, which required analysis of the

617 strain distribution up the wall height, rather than the crude estimates made here with Equation 23.

618 Furthermore, the $L_{p}$ estimates using Equation 14 were found to correlate better to the experimental

619 observations of a series of tests conducted on lightly reinforced rectangular concrete wall specimens

620 (Hoult et al., 2017).
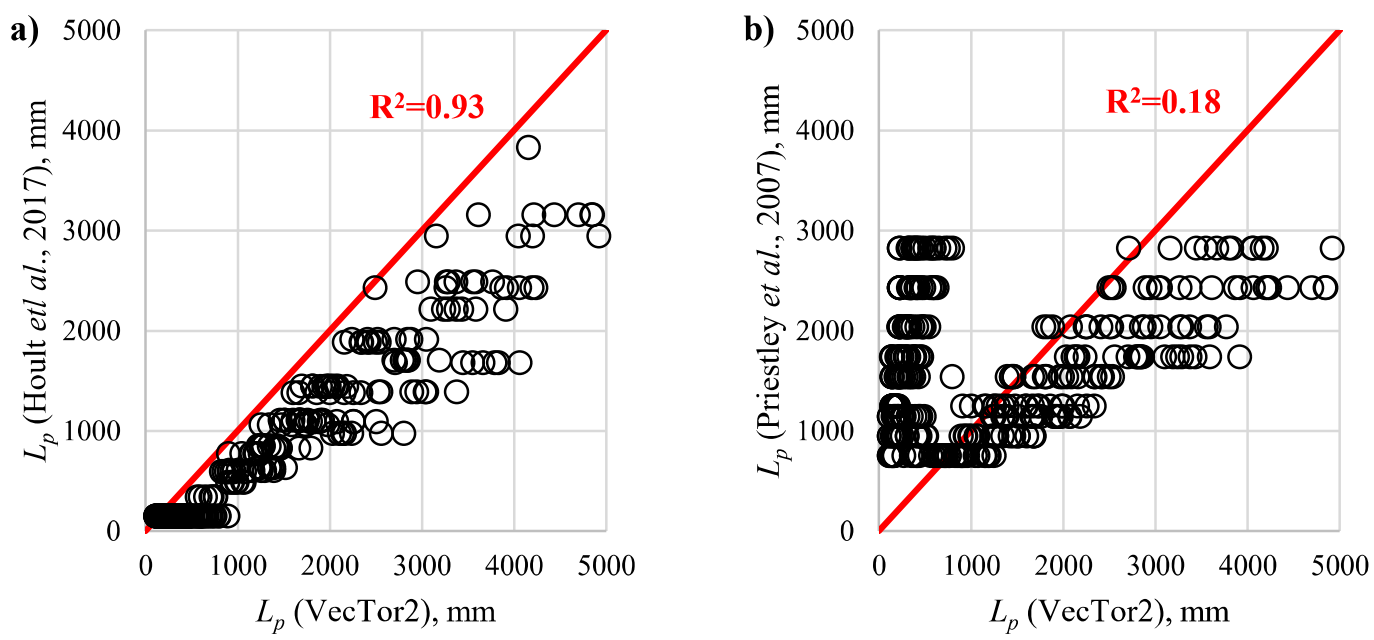

Figure 16 Equivalent plastic hinge length results from VecTor2 compared to estimates from (a) Hoult et al. (2017) and (b) (Priestley et al., 2007) 
Furthermore, Figure 17 compares the plastic displacement $\left(\Delta_{p}\right)$ from VecTor2 for all of rectangular

624 walls analysed to the estimates using Equation 10 and the corresponding $L_{p}$ equations discussed

625 above. Not surprisingly, the $\Delta_{p}$ estimates from Priestley et al. (2007) provide results with a large

626 range of scatter and primarily overestimation (Figure 17b), which is due to the $L_{p}$ expression used

627 (Equation 11). Once again, it should be noted that the $\Delta_{p}$ estimates from Priestley et al. (2007) can

produce reasonably good estimates for some of the walls, typically corresponding to the $\mathrm{RC}$ walls that

have formed secondary cracking (e.g. where $\rho_{w v} \geq \rho_{w v . m i n}$ ). In contrast, the $\Delta_{p}$ estimates using the $L_{p}$ expression from Hoult et al. (2017) correlate well to the VecTor2 data (Figure 17a).
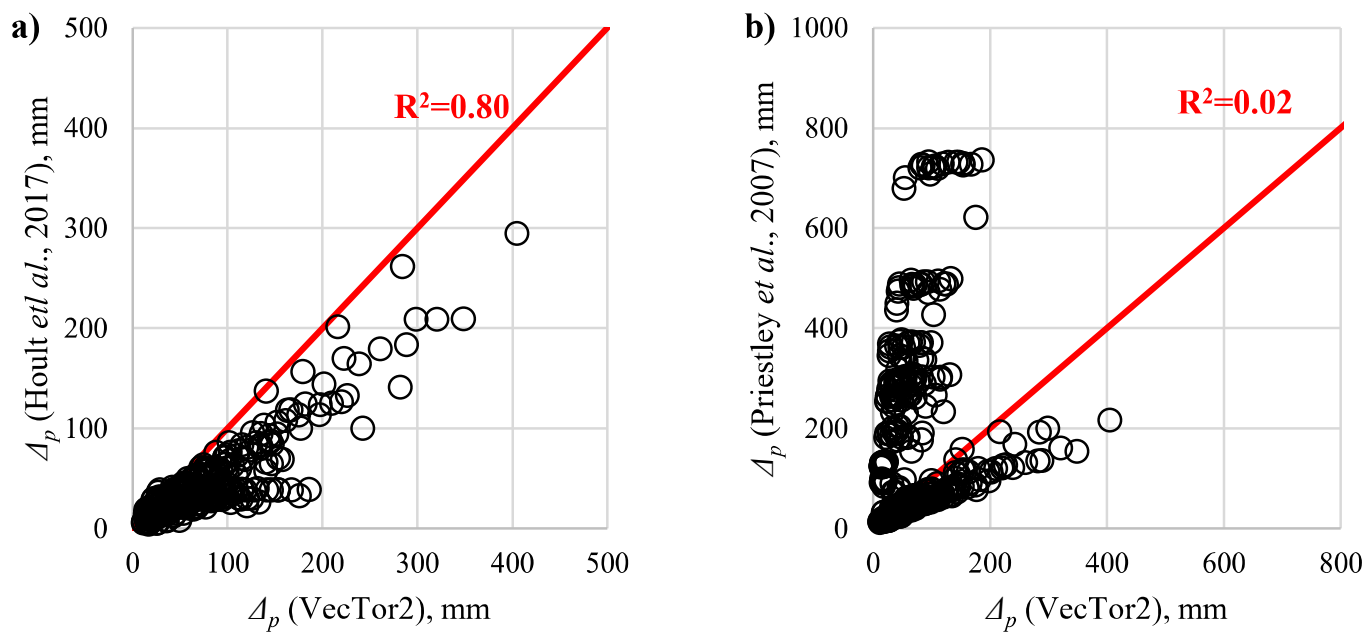

631

Figure 17 Plastic displacement results from VecTor2 compared to estimates from (a) Hoult et al. (2017) and (b) (Priestley et al., 2007)

\subsection{Displacement capacity of C-shaped walls}

The following sections investigate the yield curvature, yield displacement, plastic curvature (for single-crack C-shaped walls) and plastic displacement with respect to the different directions of bending.

\subsubsection{Yield Curvature}

\subsubsection{Major Axis}

As discussed previously in Section 2.1, a value of 1.4 is recommended to be used for $K_{l}$ when estimating $\Phi_{y}$ for C-shaped RC walls (for bending about the major axis) using Equation 9. The minimum of the sum of the squares was used with the yield curvature results from the $48 \mathrm{C}$-shaped 
walls analysed in VecTor3 such that bending about the major axis occurred. A value of 1.6 was calculated to provide the highest correlation for the $K_{l}$ parameter when using Equation 9 and comparing the estimate to the VecTor3 data. Figure 18 gives the correlation between the VecTor3 results and Equation 9 using $K_{l}$ values of 1.6 and 1.4. A slightly better correlation can be observed to be achieved by using a $K_{l}$ value of 1.6 for the type of C-shaped walls analysed here (e.g. lightly reinforced and unconfined) and for bending about the major axis. It should be noted that two of the walls that were analysed (discussed in Section 3.3), and for bending about the major axis, were subtracted from the dataset used here, as the Collapse Prevention limit strain in the concrete $\left(\varepsilon_{c}=\right.$ 0.003) was reached before yielding of the steel reinforcement.
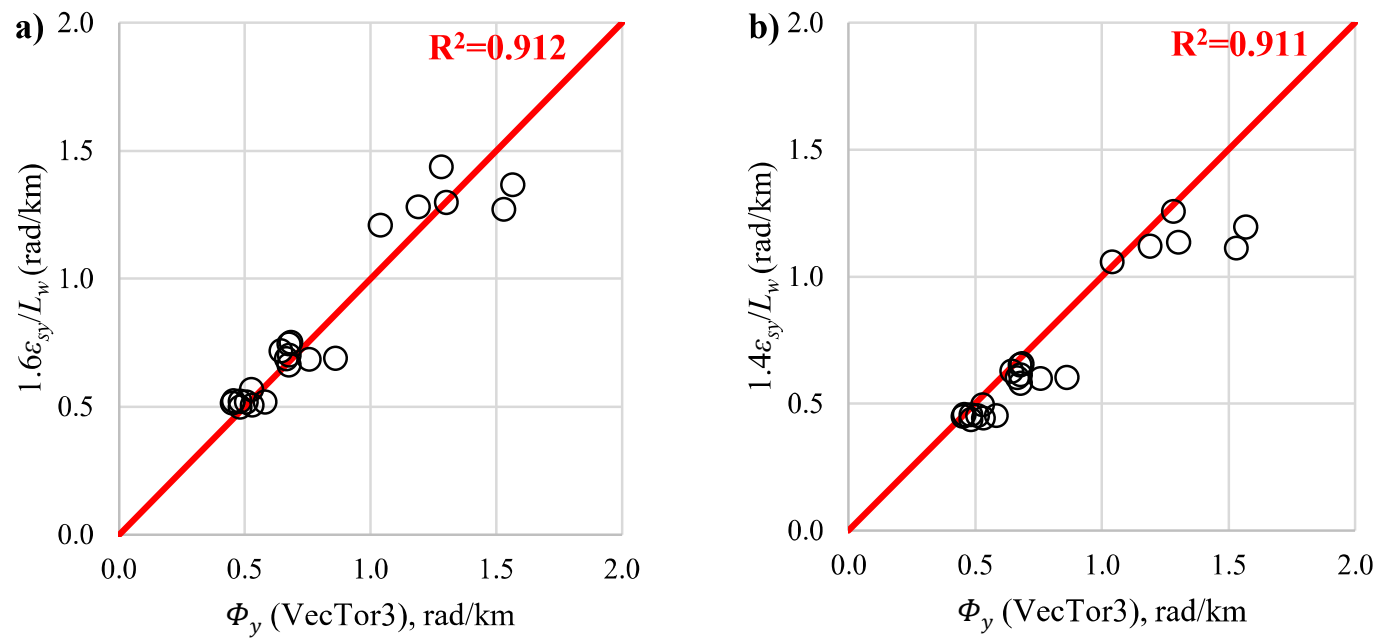

Figure 18 Nominal yield curvature correlations with a $K_{1}$ value of (a) 1.6 and (b) 1.4

\subsubsection{Minor Axis (WiC)}

Similar to the procedure used in Section 4.2.1.1, the minimum of the sum of the squares was used to find that a $K_{l}$ value of 1.45 correlated best to the VecTor3 results for the C-shaped walls bending about the minor axis (WiC) and using the yield curvature expression from Equation 9. This is close to the value of 1.40 recommended by Sullivan et al. (2012) for T-shaped and C-shaped walls for this direction of bending (discussed in Section 2.1). Therefore, a $K_{l}$ value of 1.4 is adopted for the Cshaped walls which are bending about the minor axis (WiC). The estimated values of $\Phi_{y}$ obtained using Equation 9 with a $K_{l}$ value of 1.4 are compared with the VecTor3 data in Figure 19. 


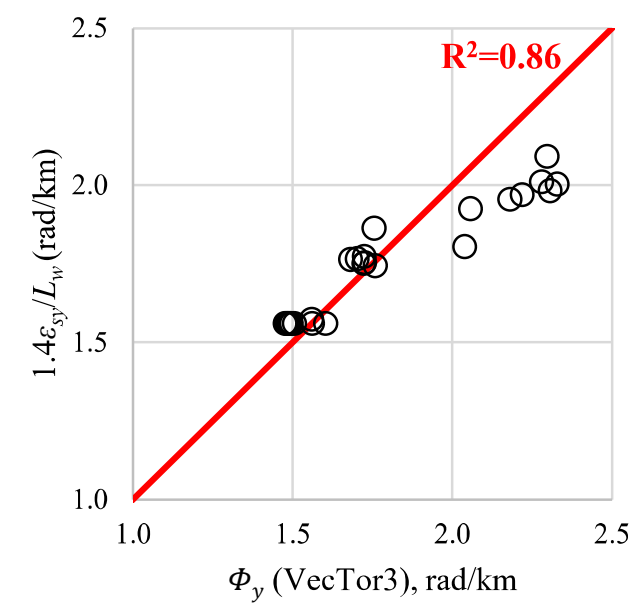

661

Figure 19 Nominal yield curvature correlations with a $K_{I}$ value of 1.4

\subsubsection{Minor Axis (WiT)}

The same process used in deriving the nominal yield curvature $\left(\Phi_{y}\right)$ in Section 4.2.1.1 and 4.2.1.2 was used here. Using the minimum of the sum of the squares, a $K_{l}$ value of 1.59 was found to correlate best to the VecTor3 results for the C-shaped walls bending about the minor axis (WiT) and using the yield curvature expression from Equation 9. Therefore, a rounded $K_{l}$ value of 1.6 was used for bending about the minor axis (WiC). Importantly, only the C-shaped walls (and bending about the minor axis with WiT) that reached or exceeded yield were used in the dataset to find the best value of $K_{l}$. This value is lower than the $K_{l}$ value of 1.8 proposed by Paulay (2002) and Sullivan et al. (2012) for T-shaped and C-shaped walls for this direction of bending (discussed in Section 2.1). A comparison is made in Figure 20 between the $\Phi_{y}$ values obtained using $K_{l}$ values of 1.6 and 1.8 to the VecTor3 results. Although the $\mathrm{R}^{2}$ value is the same using either of the $K_{l}$ values, there is clearly a more observable fit using a $K_{l}$ value of 1.6 shown in Figure 20(a). 

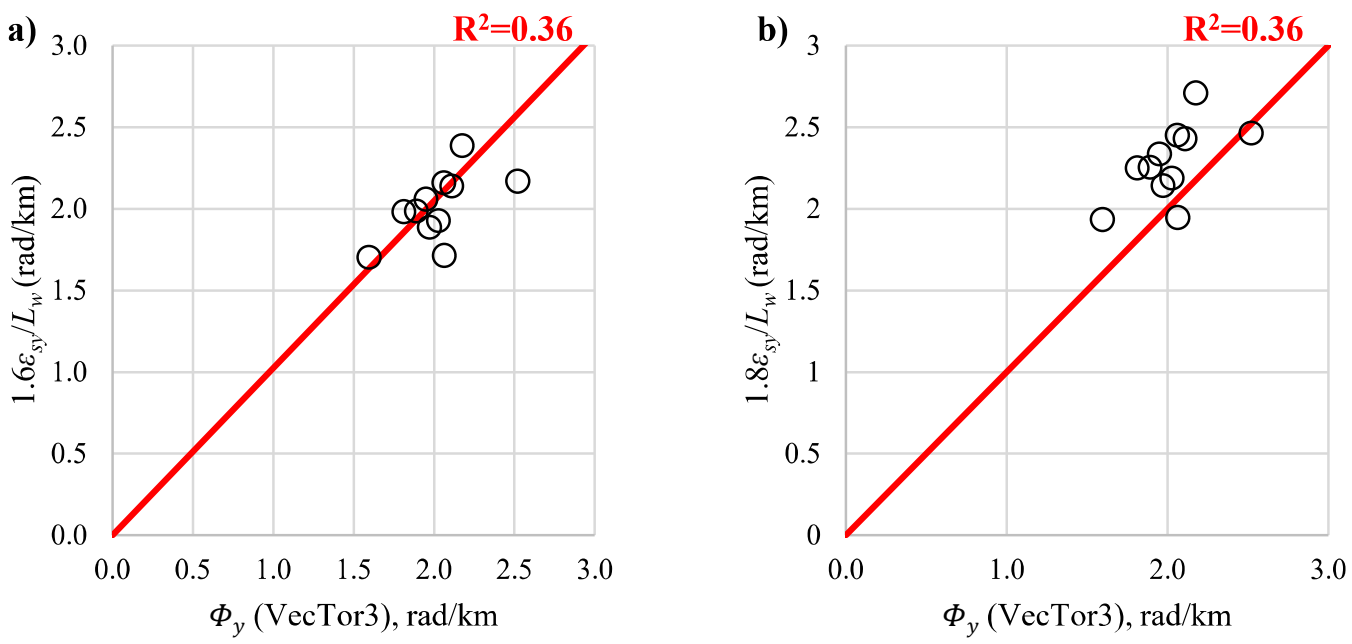

Figure 20 Nominal yield curvature correlations with a $K_{I}$ value of (a) 1.6 and (b) 1.8

\subsubsection{Yield Displacement}

The nominal yield displacement $\left(\Delta_{y}\right)$ values were calculated from VecTor3 for all of the C-shaped

walls using Equation 1, by extracting the values for $\Delta_{y}^{\prime}, F_{u}$ and $F_{y}$ from the finite element results for each increment of $\rho_{w v}$. Similar to the observations for the rectangular walls analysed in Section 4.1, the resulting values of $\Delta_{y}$ for the C-shaped walls analysed in VecTor3 were found to increase as a function of the longitudinal reinforcement ratio $\left(\rho_{w v}\right)$ of the wall. Therefore, a factor $\left(K_{4}\right)$ is proposed in Equation 24, similar to that in Section 4.1 for rectangular walls, which can be used in conjunction with the yield displacement equation proposed by Beyer (2007) (the "modified Beyer" approach).

$$
K_{\Delta}=\theta \rho_{w v}+\beta
$$
gave the highest correlating values of $\Delta_{y}$ to the VecTor3 data when using Equation 25. These values of $\theta$ and $\beta$ were derived for the three different directions of loading and are given in Table 6. reinforced and unconfined $\mathrm{C}$-shaped walls can be estimated. It should be noted that the deformations due to shear $\left(\Delta_{s} / \Delta_{f}\right)$ have been included in Equation 25. 


$$
\Delta_{y}=K_{\Delta} \Phi_{y}\left(\frac{k_{c r}}{3} H_{n}^{2}+L_{y p} H_{n}\right)\left(1+\frac{\Delta_{s}}{\Delta_{f}}\right)
$$

Table 6 Values for calculation of $K_{4}$

\begin{tabular}{cccc}
\cline { 2 - 4 } & Major & Minor (WiC) & Minor (WiT) \\
\hline$\theta$ & 80 & 50 & 100 \\
$\beta$ & 0.0 & 0.3 & 1.0 \\
\hline
\end{tabular}

690

691 Figure 21 illustrate the different correlations of $\Delta_{y}$ from the C-shaped wall results analysed in

692 VecTor3 to the estimated values of $\Delta_{y}$ using the expressions proposed by Priestley et al. (2007)

693 (Equation 2), Beyer (2007) (Equation 3) and the modified Beyer approach (Equation 25). It should be noted that the same values of $\Phi_{y}$ for each of the different walls were used in all of the expressions, which were determined using Equation 9 and the $K_{l}$ values derived from Section 4.2.1 (corresponding to the different directions of loading). Furthermore, to determine the deformations due to shear $\left(\Delta_{s} /\right.$ $\Delta_{f}$ ), a conservative cracking angle of $30^{\circ}$ has been assumed, which was a value recommended in

698 Priestley et al. (1996) to be used for assessment purposes. Similar to the findings for the rectangular walls, it is clear that by including the $K_{\Delta}$ parameter proposed here for lightly reinforced and unconfined C-shaped walls, the estimate of $\Delta_{y}$ can be significantly improved.
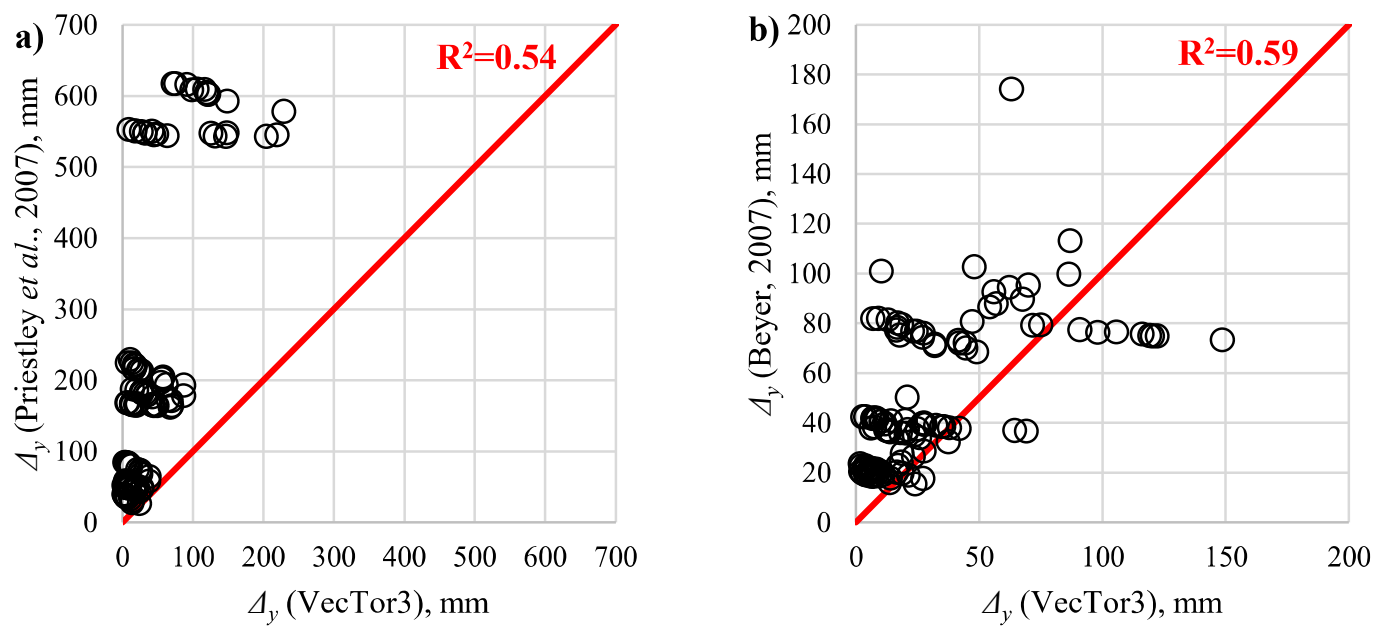


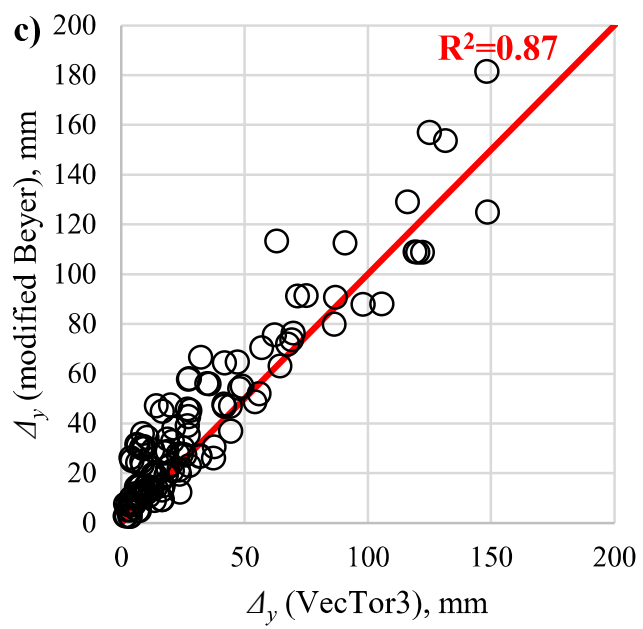

Figure 21 Yield Displacement using expression proposed from (a) Priestley et al. (2007) (b) Beyer (2007) and (c) modified Beyer

\subsubsection{Plastic curvature of single-crack C-shaped walls}

It was discussed in Section 4.1.2 that a typical moment-curvature analysis may not be able to predict the ultimate curvature achieved by single-crack failure walls. Therefore, Equation 22 (in Section 4.1.2) should also be used to calculate the plastic curvature $\left(\Phi_{p}\right)$ for the C-shaped walls with, (i) insufficient longitudinal reinforcement to allow secondary cracking $\left(\rho_{w v}<\rho_{w v \text { min }}\right)$ and (ii) governed by tension strains (in the steel). It should be noted that $L_{w}$ in Equation 22 corresponds to the wall length parallel to the direction of loading for the C-shaped walls. The estimated $\Phi_{p}$ values using Equation 22 are compared to the $\Phi_{p}$ values determined from VecTor3 in Figure 22 for the C-shaped walls that conform to the criteria above, where a good fit is achieved. 


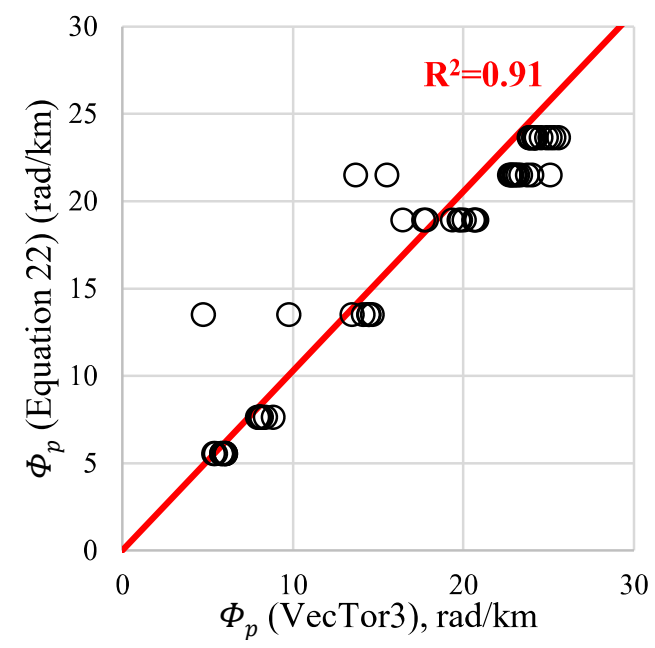

Figure 22 Plastic curvature comparisons for the C-shaped walls

\subsubsection{Plastic Displacement}

715 Similar to Section 4.1.3, the $L_{p}$ was estimated from the VecTor3 results for the C-shaped walls by

716 rearranging Equation 10. These results are compared to the estimated $L_{p}$ from Hoult et al. (2018)

717 (Equation 16 - 18) and Constantin (2016) (Equation 13) in Figure 23. The $L_{p}$ estimates from Hoult 718 et al. (2018), specifically derived for lightly reinforced and unconfined C-shaped walls, achieve a 719 higher correlation and better fit to the VecTor3 data in comparison to the estimates from Constantin 720 (2016), which in contrast give a large scatter of results. Importantly, the great majority of the 721 estimated $L_{p}$ values using the expression from Hoult et al. (2018) resulted in conservative values in 722 comparison to the VecTor3 data. The higher correlation of the estimated $L_{p}$ values using the 723 expressions from Hoult et al. (2018) to the VecTor3 data, in comparison to the expressions from 724 Constantin (2016), is not all that surprising; the same VecTor3 data that is used for comparisons 725 here was also used to derive the expressions from Hoult et al. (2018) (Equation 16 to 18), while the 726 expression from Constantin (2016) was derived from numerical and experimental results of highly 727 reinforced and well confined C-shaped wall specimens. 

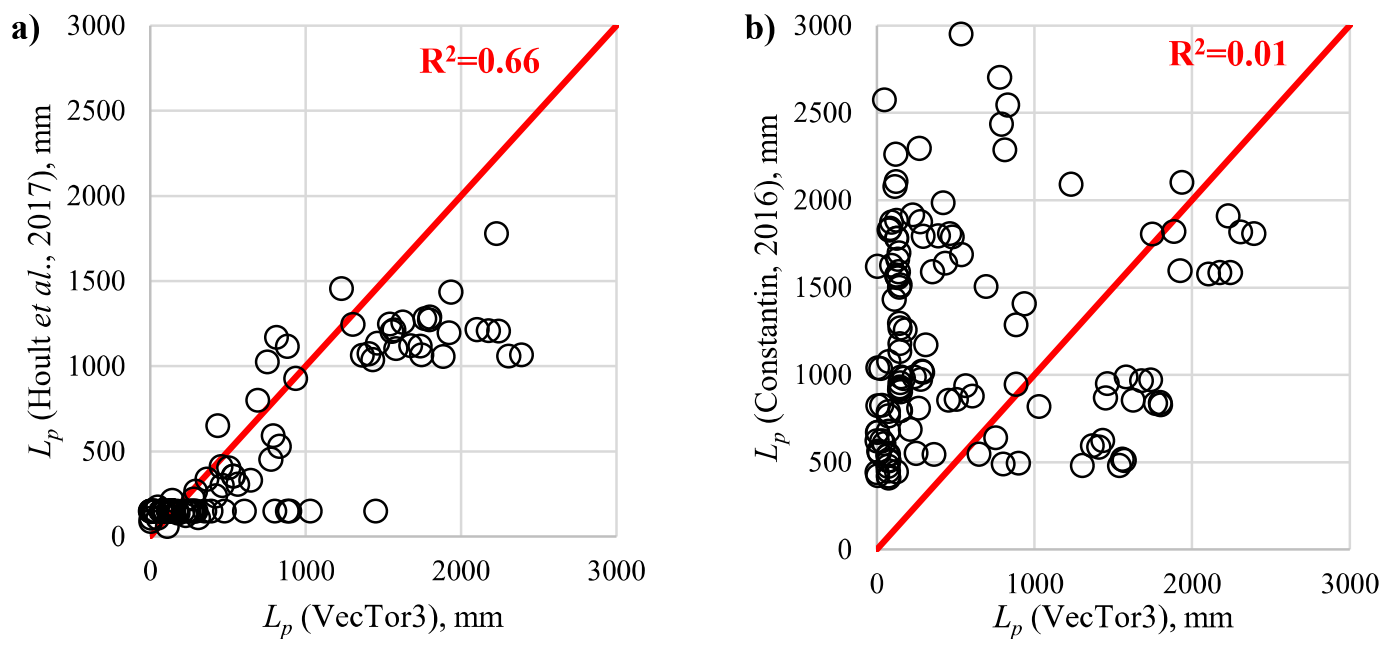

Figure 23 Equivalent plastic hinge length results from VecTor3 compared to estimates from (a) Hoult $e t$ al. (2017) and (b) (Priestley et al., 2007)

The plastic displacement $\left(\Delta_{p}\right)$ of all of the C-shaped walls analysed in VecTor3 were found by subtracting the nominal yield displacement $\left(\Delta_{y}\right)$ found in Section 4.2.2 from the ultimate displacement capacity of the wall $\left(\Delta_{u}\right)$. The values of $\Delta_{p}$ obtained from the numerical analyses can be compared to the values of $\Delta_{p}$ calculated from PHA (Equation 10). The values of $\Phi_{u}$ used in Equation 10 were calculated directly from the VecTor3 results (i.e. from the respective compression and tension strains in the extreme fibre regions at the base of the wall), while the $L_{p}$ was estimated using the expressions from Hoult et al. (2018) and Constantin (2016) given in Section 2.2. The shear-to-flexure ratio $\left(\Delta_{s} /\right.$ $\Delta_{f}$ ) was calculated using a conservative cracking angle of $30^{\circ}$. In general, the calculated plastic displacement, using the $L_{p}$ expressions from Hoult et al. (2018), correlated well to the $\Delta_{p}$ found from VecTor3 for all of the walls and directions of loading, as illustrated in Figure 24(a). In some cases, and in particular for the HR walls, the calculated value of $\Delta_{p}$ was found to be conservative. The cause of this underestimation was likely to be due to the low $L_{p}$ estimate (of $150 \mathrm{~mm}$ ) for "single-crack" walls, when in fact some HR walls were found to form several primary cracks and thus increase the plastic deformation of the walls. Not surprisingly, the $\Delta_{p}$ estimates using the $L_{p}$ expression from Constantin (2016) in Figure 24(b) provide results with a large range of scatter and primarily overestimation. 

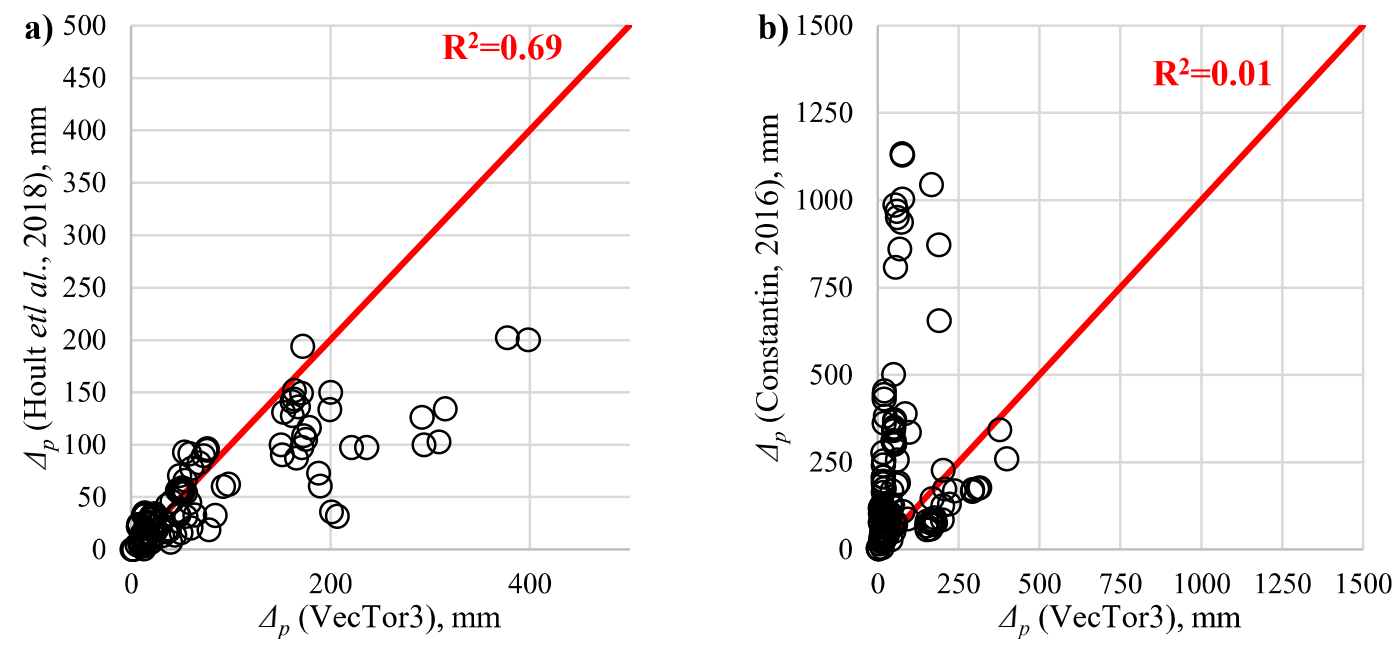

\section{Figure 24 Plastic displacement results from VecTor3 compared to estimates from (a) Hoult et al. (2018)} and (b) Constantin (2016)

\subsubsection{Elastic Displacement}

For some of the C-shaped walls analysed in VecTor3 (and for bending about the minor axis with WiT), the longitudinal steel in the extreme tension fibre region did not reach (or exceed) the yield strain prior to failure; the failure was caused by the ultimate unconfined compression strain being reached at the boundary ends of the flanges (extreme compression fibre region of the wall).

Therefore, the proposed expressions for estimating the displacement corresponding to the "Serviceability" performance level $\left(\Delta_{s}\right)$ for these types of walls and for this direction of loading is given in Equation 26, i.e. it is assumed that a plastic hinge does not form. It should be noted that the Serviceability performance level for unconfined concrete walls has been taken here as when $\varepsilon_{c}$ reaches -0.001 , where the concrete stress-strain curve is close to linear.

$$
\Delta_{s}=\frac{P H_{e}^{3}}{3 E_{c} I_{e f f}}=\frac{M H_{e}^{2}}{3 E_{c} I_{e f f}}
$$

where $M$ is the moment corresponding to a performance level, $E_{c}$ is the Young's modulus of the concrete and $I_{\text {eff }}$ is the effective moment of inertia.

For the purposes of this study, the $I_{\text {eff }}$ is taken as 0.8 of the gross cross-sectional moment of inertia $\left(0.8 I_{g}\right)$, which has been adopted from ASCE (2007) for uncracked concrete sections. A factor of 0.8 of the $I_{g}$ was found to correspond well to the displacement of these walls at the Serviceability 
performance level $\left(\Delta_{s}\right)$, as shown in Figure 25(a). It should be noted that the $E_{c}$ is taken as $5000 \sqrt{f_{c}^{\prime}}$, taken from AS 3600:2009 (Standards Australia, 2009), where $f_{c m i}$ is used as substitute for the $f^{\prime}$ ' value. The displacement for the Damage Control and Collapse Prevention performance levels $\left(\Delta_{d c}\right.$ and $\left.\Delta_{c p}\right)$ can be found by using a factor $(\Omega)$ to increase the calculated $\Delta_{s}$. The minimum of the sum of squares is used to determine the best value of $\Omega$ for each performance level using the VecTor3 data for all of the walls that remained "elastic" and for bending about the minor axis (WiT). Table 7 gives the resulting values of $\Omega$ corresponding to the different performance levels. It should be noted that the Damage Control performance level for unconfined concrete walls has been taken here as when $\varepsilon_{c}$ reaches -0.002 , where the concrete is now expected to be in the non-linear range but there is a low expectation (small margin) of spalling.

Table 7 Different values of $\Omega$ for the performance levels

\begin{tabular}{|c|c|}
\hline \multicolumn{2}{|c|}{ Performance Level } \\
\hline Damage Control & Collapse Prevention \\
\hline 1.5 & 1.8 \\
\hline
\end{tabular}

Figure 25(a) shows the goodness of the fit from using Equation 26 for $\Delta_{s}$. Moreover, the goodness of the fit is shown for $\Delta_{d c}$ and $\Delta_{c p}$ in Figure 25(b) and Figure 25(c) respectively by using the different values of $\Omega$ in Table 7. It should be noted that the corresponding force $(P)$ used in Equation 26 to calculate these values was taken from VecTor3. Alternatively, the moment $(M)$ could be used in Equation 26 to determine the Serviceability displacement capacity, which can be found from a moment-curvature (or sectional) analysis. Moreover, three examples of the resulting forcedisplacement relationship are given in Figure 26 by using Equation 26 and the $\Omega$ values in Table 7 . These resulting force-displacement plots have been compared to the LR, MR and HR C-shaped walls that have been analysed in VecTor3 (and have remained essentially "elastic" up until failure). These walls were chosen for the purpose of illustration; they all have an $f_{c m i}$ of $40 \mathrm{MPa}$ and an $A L R$ of $5 \%$, while the $\rho_{w v}$ of the LR and MR walls is $0.70 \%$ and the $\rho_{w v}$ of the HR wall is $1.00 \%$. It is shown that the displacement estimates using Equation 26 and the $\Omega$ values proposed here for the different 

modelling analyses in VecTor3.
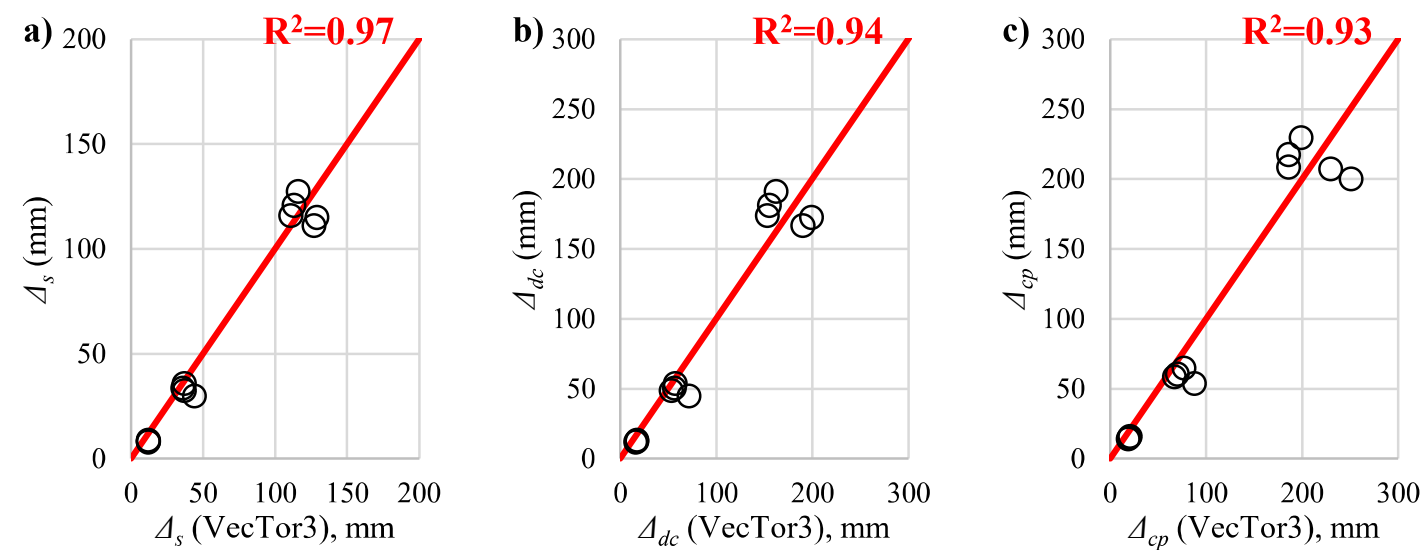

Figure 25 VecTor3 displacements compared to the displacements predicted for (a) Serviceability (b) Damage Control and (c) Collapse Prevention
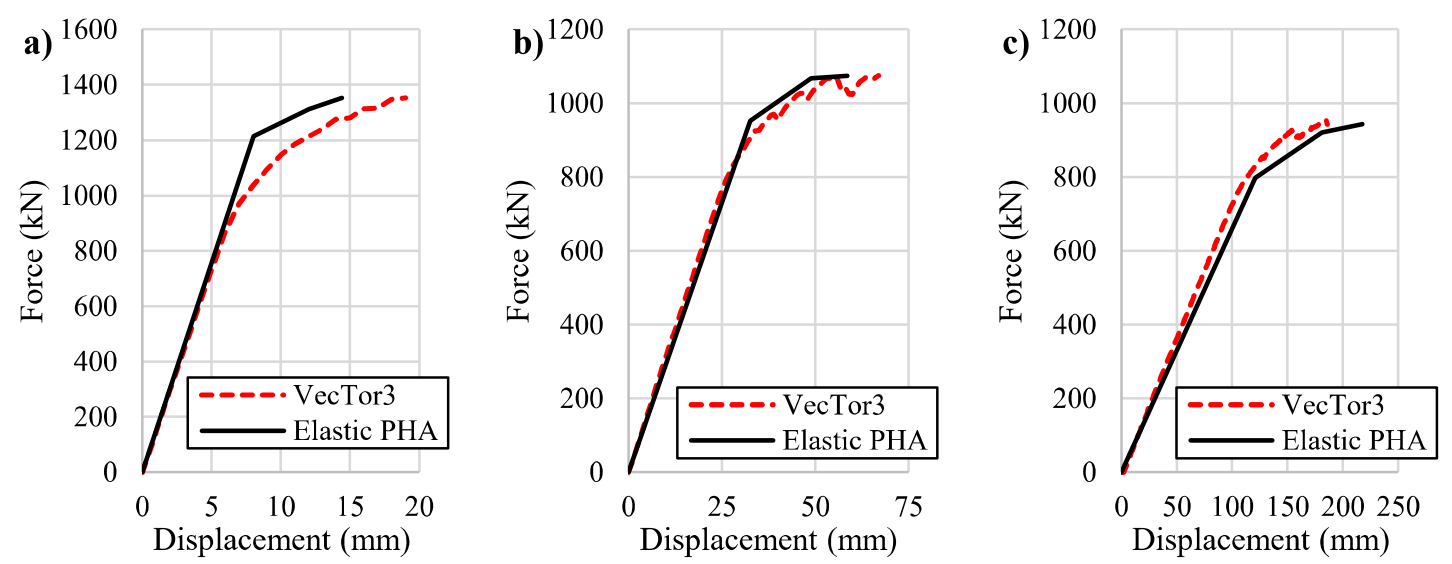

Figure 26 Force-displacement relationship for (a) LR (b) MR and (c) HR C-shaped wall that remained elastic

\section{Summary of recommended expressions}

In summary, the following equations are recommended to be used (for assessment) in calculating the displacement capacity of lightly reinforced and unconfined rectangular and C-shaped walls using plastic hinge analysis. Different equations for the plastic displacement are recommended depending on the ratio of the longitudinal reinforcement ratio $\left(\rho_{w v}\right)$ to the minimum longitudinal reinforcement ratio $\left(\rho_{w v \cdot \min }\right)$ required to allow secondary cracking: 
$801 \Phi_{y}=\frac{K_{1} \varepsilon_{s y}}{L_{w}}$

\begin{tabular}{ccccc}
\cline { 3 - 5 } & & \multicolumn{3}{c}{ C-Shaped } \\
\cline { 2 - 5 } & Rectangular & Major & $\begin{array}{c}\text { Minor } \\
(\text { WiC) }\end{array}$ & $\begin{array}{c}\text { Minor } \\
(\text { WiT) }\end{array}$ \\
\hline$K_{I}$ & 1.7 & 1.6 & 1.4 & 1.6 \\
\hline
\end{tabular}

802

803 Shear Displacement

$804 \frac{\Delta_{s}}{\Delta_{f}}=1.5\left(\frac{\varepsilon_{m}}{\Phi_{u} \tan \theta_{c}}\right)\left(\frac{1}{H_{e}}\right)$, or $\frac{\Delta_{s}}{\Delta_{f}}=0$ for rectangular walls with $A_{r}>2$

$805 \quad$ Yield Displacement

$806 K_{\Delta}=\theta \rho_{w v}+\beta$

807

\begin{tabular}{ccccc}
\cline { 3 - 5 } & & \multicolumn{3}{c}{ C-Shaped } \\
\cline { 2 - 5 } & Rectangular & Major & $\begin{array}{c}\text { Minor } \\
(\text { WiC) }\end{array}$ & $\begin{array}{c}\text { Minor } \\
(\text { WiT })\end{array}$ \\
\hline$\theta$ & 45 & 80 & 50 & 100 \\
$\beta$ & 0.22 & 0.00 & 0.30 & 1.00 \\
\hline
\end{tabular}

$808 \alpha=\frac{M_{y}^{\prime} / \Phi_{y}^{\prime}}{E_{c} I_{g}}$

$809 \quad H_{c r}=\max \left(L_{w},\left(1-\frac{M_{c r}}{M_{y}^{\prime}}\right) H_{n}\right)$

$810 \quad k_{c r}=\alpha+0.5(1-\alpha)\left(\frac{3 H_{c r}}{H_{n}}-\frac{H_{c r}^{2}}{H_{n}^{2}}\right)$

$811 \Delta_{y}=K_{\Delta} \Phi_{y}\left(\frac{k_{c r}}{3} H_{n}^{2}+L_{y p} H_{n}\right)\left(1+\frac{\Delta_{s}}{\Delta_{f}}\right)$

$812 \quad$ Plastic Displacement

$813 \rho_{w v . \min }=\frac{\left(t_{w}-n_{t} d_{b t}\right) f_{c t . f l}}{f_{u} t}$ 


$$
\begin{aligned}
& 814 \quad \text { If } \frac{\rho_{w v}}{\rho_{w v \cdot \min }} \leq 1 \\
& 815 \Phi_{p}=\frac{0.6 \varepsilon_{s u}-\varepsilon_{s y}}{L_{w}} \text { and } L_{p}=150 \mathrm{~mm} \\
& 816 \quad \text { If } \frac{\rho_{w v}}{\rho_{w v \cdot \min }}>1
\end{aligned}
$$

$817 \Phi_{p}$ to be determined from moment-curvature analysis

$818 L_{\text {p.rectangular }}=\left(0.1 L_{w}+0.075 H_{e}\right)(1-6 A L R) \leq 0.5 L_{w}$

$819 L_{\text {p.major }}=\left(0.1 L_{\text {web }}-0.013 H_{e}\right)(1-13 A L R)\left(7 e^{-0.8 v}\right) \leq 0.5 L_{\text {web }}$

$820 L_{\text {p.minor.WiC }}=\left(0.5 L_{\text {flange }}-0.015 H_{e}\right)(1-3 A L R)\left(1.6 e^{-0.1 v}\right) \leq L_{\text {flange }}$

$821 L_{\text {p.minor.WiT }}=\left(1.0 L_{\text {flange }}-0.073 H_{e}\right)(1-8 A L R)\left(2.5 e^{-2.1 v}\right) \leq 0.5 L_{\text {flange }}$

$822 \Delta_{p}=L_{p}\left(\Phi_{u}-\Phi_{y}\right) H_{e}\left(1+\frac{\Delta_{s}}{\Delta_{f}}\right)$

$823 \quad$ Ultimate Displacement

$824 \Delta_{u}=\Delta_{y}+\Delta_{p}$

825 6. Conclusions

826 The current expressions that exist in the literature for determining the displacement of reinforced

827 concrete walls using a plastic hinge analysis cannot be used to accurately estimate the capacity of

828 lightly reinforced members that are commonly found in low-to-moderate seismic regions. This was

829 shown in this research investigation by comparing the displacement capacity results of 378

830 rectangular and $144 \mathrm{C}$-shaped lightly reinforced and unconfined concrete walls analysed in finite

831 element modelling to the commonly used plastic hinge analysis expressions. Importantly, the

832 assumption of a linear curvature profile up the wall height at first yield was vastly different to the

833 actual yield curvature profile obtained from all of the finite element modelling results. Thus, a

834 parameter was derived $\left(K_{4}\right)$ to be included in the expression that is recommended by Beyer $(2007)$ to

835 modify the estimated yield displacement for lightly reinforced walls ("the modified Beyer" approach). 
836 The value of $K_{\Delta}$ is dependent on the longitudinal reinforcement ratio $\left(\rho_{w v}\right)$ of the wall, as the results of

837 the lightly reinforced concrete walls from finite element modelling showed that the $\Delta_{y}$ increased as a

838 function of the $\rho_{w v}$. A higher correlation of the values for the nominal yield displacement was

839 achieved between the finite element modelling results and the plastic hinge analysis expression from

840 Beyer (2007) with the inclusion of the $K_{\Delta}$ term. Other recommendations from this research include an

841 expression for the estimation of the plastic curvature for when a single, primary crack is expected to

842 occur; the onset of secondary cracking can be predicted by comparing the $\rho_{w v}$ of the wall to the

843 minimum longitudinal reinforcement ratio $\left(\rho_{w v \cdot \min }\right)$ required to initiate secondary cracking. This is

844 important, as it is expected that a moment-curvature analysis will provide a poor estimate of the strain

845 penetration moment and curvature due to the moment-curvature (or sectional) analysis inherently

846 assuming a flexurally dominant performance of the wall.

847 The expressions recommended in this research for lightly reinforced and unconfined rectangular and

848 C-shaped walls will provide better estimates of the displacement capacity when using plastic hinge

849 analyses. Thus, this will ultimately provide more accurate estimates of the capacity of RC structural

850 (or shear) wall buildings in low-to-moderate seismic regions, such as Australia, and aid in providing

851 more accurate vulnerability studies.

852 While this research primarily focused on the displacement capacity of RC walls due to flexural

853 actions, the authors acknowledge the potential for other contributions to the overall displacement

854 capacity of a RC wall, such as shear and slip, or other modes of failure, such as out-of-plane buckling

855 due to lack of confinement. Therefore, the results and expressions derived from this research

856 investigation are limited to the capabilities of the models used (e.g. VecTor2, VecTor3 and PHA) and

857 issues, such as out-of-plane buckling, were neglected. It is recommended that further experimental

858 testing be conducted on lightly reinforced and unconfined walls to gain a better understanding of these

859 unwarranted failure modes.

$860 \quad$ 7. Acknowledgements 
acknowledged.

\section{References}

ACI. (2011). Building code requirements for structural concrete: (ACI 318-11) ; and Commentary: American Concrete Institute.

Adebar, P., \& Lorzadeh, A. (2012). Compression Failure of Thin Concrete Walls. Paper presented at the 15 th World Conference on Earthquake Engineering.

Albidah, A. (2016). Vulnerability and Risks of Collapse of Structural Concrete Walls in Regions of Low to Moderate Seismicity. (Doctor of Philosophy), The University of Melbourne.

Albidah, A., Altheeb, A., Lam, N., \& Wilson, J. (2013). A Reconnaissance Survey on Shear Wall Characteristics in Regions of Low-to-Moderate Seismicity. Paper presented at the Paper presented at the Australian Earthquake Engineering Society 2013 Conference, Hobart, VIC.

Almeida, J. P., Tarquini, D., \& Beyer, K. (2016). Modelling Approaches for Inelastic Behaviour of RC Walls: Multi-level Assessment and Dependability of Results. Archives of Computational Methods in Engineering, 23(1), 69-100.

Altheeb, A. (2016). Seismic Drift Capacity of Lightly Reinforced Concrete Shear Walls. (Doctor of Philosophy), The University of Melbourne.

ASCE. (2007). Seismic rehabilitation of existing buildings (Vol. 41): American Society of Civil Engineers Publications.

Beca. (2011). Investigation into the collapse of the Pyne Gould Corporation Building on 22nd February 2011, Report. 46 pp. Retrieved from

Belletti, B., Damoni, C., \& Gasperi, A. (2013). Modeling approaches suitable for pushover analyses of RC structural wall buildings. Engineering Structures, 57, 327-338. doi:http://dx.doi.org/10.1016/j.engstruct.2013.09.023

Beyer, K. (2007). Seismic design of torsionally eccentric buildings with U-shaped RC Walls. (PhD), ROSE School. (ROSE-2008/0X)

Beyer, K., Dazio, A., \& Priestley, M. J. N. (2008a). Inelastic Wide-Column Models for U-Shaped Reinforced Concrete Walls. Journal of Earthquake Engineering, 12(sup1), 1-33. doi:10.1080/13632460801922571

Beyer, K., Dazio, A., \& Priestley, M. J. N. (2008b). Quasi-Static Cyclic Tests of Two U-Shaped Reinforced Concrete Walls. Journal of Earthquake Engineering, 12(7), 1023-1053. doi:10.1080/13632460802003272

Beyer, K., Dazio, A., \& Priestley, M. J. N. (2011). Shear Deformations of Slender Reinforced Concrete Walls under Seismic Loading. ACI Structural Journal, 108(2), 167-177.

Bohl, A., \& Adebar, P. (2011). Plastic Hinge Lengths in High-Rise Concrete Shear Walls. ACI Structural Journal, 108(2), 148-157.

Bradley, B. A., Quigley, M. C., Van Dissen, R. J., \& Litchfield, N. J. (2014). Ground motion and seismic source aspects of the Canterbury earthquake sequence. Earthquake Spectra, 30(1), 115.

Brown, A., \& Gibson, G. (2004). A multi-tiered earthquake hazard model for Australia. Tectonophysics, 390(1-4), 25-43.

Cardenas, A. E., \& Magura, D. D. (1972). Strength of High-Rise Shear Walls - Rectangular Cross Section. Special Publication, 36. doi:10.14359/17361

CERC. (2012). Canterbury Earthquakes Royal Commission. Final report: Volume 2: The performance of Christchurch CBD Buildings. Wellington, NZ.

Constantin, R. (2016). Seismic behaviour and analysis of U-shaped RC walls. École polytechnique fédérale de Lausanne, Lausanne, Switzerland.

Constantin, R., \& Beyer, K. (2016). Behaviour of U-shaped RC walls under quasi-static cyclic diagonal loading. Engineering Structures, 106, 36-52. doi:http://dx.doi.org/10.1016/j.engstruct.2015.10.018 
Dai, H. (2011). An Investigation of Ductile Design of Slender Concrete Structural Walls. (Master of Science), Iowa State University, Ames, Iowa.

ElMohandes, F. (2013). Advanced Three-Dimensional Nonlinear Analysis of Reinforced Concrete Structures Subjected to Fire and Extreme Loads. (Doctor of Philosophy), University of Toronto, Toronto, Canada.

ElMohandes, F., \& Vecchio, F. (2013). Vector3 and FormWorks Plus User Manual. Department of Civil Engineering, University of Toronto. Retrieved from http://www.civ.utoronto.ca/vector/user_manuals/manual6.pdf

FEMA. (2010). HAZUS MH MR5 Technical Manual. Washington, D.C.

Fenwick, R., \& Dhakal, R. P. (2007). Material strain limits for seismic design of concrete structures. SESOC: Journal of the NZ Structural Engineering Society, 20(1), pp. 14-28.

fib, F. I. d. B. (2012). Model Code 2010 - Final draft, Volume 2. fib Bulletin No. 66. Lausanne, Switzerland.

Ghorbani-Renani, I., Velev, N., Tremblay, R., Palermo, D., Massicotte, B., \& Léger, P. (2009). Modeling and Testing Influence of Scaling Effects on Inelastic Response of Shear Walls. Structural Journal, 106(3). doi:10.14359/56500

Goldsworthy, H. M. (2012). Lessons on building design from the 22 February 2011 Christchurch earthquake. Australian Journal of Structural Engineering, 13(2), 159.

Hannewald, P. (2013). Seismic Behavior of Poorly Detailed RC Bridge Piers. (PhD thesis), EPFL. Retrieved from http://infoscience.epfl.ch/record/188364

Henry, R. S. (2013). Assessment of the Minimum Vertical Reinforcement Limits for RC Walls. Bulletin of the New Zealand Society for Earthquake Engineering, 46(2), 88.

Hines, E. M., Restrepo, J. I., \& Seible, F. (2004). Force-Displacement Characterization of WellConfined Bridge Piers. Structural Journal, 101(4). doi:10.14359/13340

Hoult, R. (2017). Seismic assessment of reinforced concrete walls in Australia. (PhD), University of Melbourne. Retrieved from http://hdl.handle.net/11343/192443

Hoult, R., Goldsworthy, H., \& Lumantarna, E. (2018). Plastic Hinge Length for Lightly Reinforced Cshaped Concrete Walls. Journal of Earthquake Engineering, 1-32. doi:10.1080/13632469.2018.1453419

Hoult, R., Goldsworthy, H., \& Lumantarna, E. (2017). Plastic Hinge Length for Lightly Reinforced Rectangular Concrete Walls. Journal of Earthquake Engineering. doi:10.1080/13632469.2017.1286619

Ile, N., \& Reynouard, J. M. (2005). Behaviour of U-shaped Walls Subjected to Uniaxial and Biaxial Cyclic Lateral Loading. Journal of Earthquake Engineering, 09(01), 67-94.

Kazaz, 1. (2013). Analytical Study on Plastic Hinge Length of Structural Walls. Journal of Structural Engineering(11), 1938.

Krolicki, J., Maffei, J., \& Calvi, G. M. (2011). Shear Strength of Reinforced Concrete Walls Subjected to Cyclic Loading. Journal of Earthquake Engineering, 15(sup1), 30-71. doi:10.1080/13632469.2011.562049

Kupfer, H. B., \& Gerstle, K. H. (1973). Behavior of Concrete under Biaxial Stresses. Journal of the Engineering Mechanics Division, 99(4), 13.

Lestuzzi, P., \& Bachmann, H. (2007). Displacement ductility and energy assessment from shaking table tests on RC structural walls. Engineering Structures, 29(8), 1708-1721. doi:http://dx.doi.org/10.1016/j.engstruct.2006.09.009

Lowes, L., Lehman, D., Kuchma, D., Mock, A., \& Behrouzi, A. (2013). Large-Scale Tests of Cshaped Reinforced Concrete Walls. from NEES Project Warehouse http:///nees.org/warehouse/project/104

Lu, Y., Henry, R. S., \& Ma, Q. (2014). Modelling and Experimental Plan of Reinforced Concrete Walls with Minimum Vertical Reinforcement. Paper presented at the Tenth U.S. National Conference on Earthquake Engineering, Anchorage, Alaska.

Lu, Y., Henry, R. S., Gultom, R., \& Ma, Q. (2015). Experimental testing and modelling of reinforced concrete walls with minimum vertical reinforcement. Paper presented the $2015 \mathrm{New}$ Zealand Society for Earthquake Engineering Annual Technical Conference, Rotorua, New Zealand. 
Luu, H., Ghorbanirenani, I., Léger, P., \& Tremblay, R. (2013). Numerical Modeling of Slender Reinforced Concrete Shear Wall Shaking Table Tests Under High-Frequency Ground Motions. Journal of Earthquake Engineering, 17(4), 517-542. doi:10.1080/13632469.2013.767759

Maqsood, T., Wehner, M., Ryu, H., Edwards, M., Dale, K., \& Miller, V. (2014). GAR15 Regional Vulnerability Functions Record 2014/38: Geoscience Australia: Canberra.

Menegon, S. J., Tsang, H. H., \& Wilson, J. L. (2015). Overstrength and ductility of limited ductile RC walls: from the design engineers perspective. Paper presented at the Proceedings of the Tenth Pacific Conference on Earthquake Engineering, Sydney, Australia.

Menegon, S. J., Wilson, C. J. N., Lam, N. T. K., \& Gad, E. F. (2017). Experimental Testing of Reinforced Concrete Walls in Regions of Lower Seismicity. Bulletin of the New Zealand Society for Earthquake Engineering, 50(4).

Moehle, J. (2015). Seismic design of reinforced concrete buildings. New York, N.Y.: McGraw-Hill Education LLC.

Morris, G. J., Bull, D. K., \& Bradley, B. A. (2015). In Situ Conditions Affecting the Ductility Capacity of Lightly Reinforced Concrete Wall Structures in the Canterbury Earthquake Sequence. Bulletin of the NZ Society of Earthquake Engineering, 48(3), 191-204.

Oesterle, R. G., Aristizabal-Ochoa, J. D., Fiorato, A. E., Russel, H. E., \& Corley, W. G. (1979). Earthquake Resistant Structural Walls: Tests of Isolated Walls : Phase II. Skokie, IL: Construction Technology Laboratories, Portland Cement Association.

Oesterle, R. G., Fiorato, A. E., Johal, L. S., Carpenter, J. E., Russell, H. G., \& Corley, W. G. (1976). Earthquake Resistant Structural Walls - Tests of Isolated Walls.

Park, R. (1989). Evaluation of ductility of structures and structural assemblages from laboratory testing. Bulletin of the New Zealand National Society for Earthquake Engineering, 22(3), $155-166$.

Paulay, T. (1986). The Design of reinforced concrete ductile shear walls for earthquake resistance: University of canterbury, Department of Civil Engineering.

Paulay, T. (2002). The displacement capacity of reinforced concrete coupled walls. Engineering Structures, 24(9), 1165-1175. doi:http://dx.doi.org/10.1016/S0141-0296(02)00050-0

Pegon, P., Plumier, C., Pinto, A., Molina, J., Gonzalez, P., Tognoli, P., \& Hubert, O. (2000). Ushaped-wall: Description of the experimental set-up TMR-ICONS-TOPIC5 (pp. 23): JRC Ispra.

Peña, O. A. H. d. 1. (2001). Modelling and Analysis of Retrofitted Reinforced Concrete Structures. (Master of Applied Science), University of Toronto. Retrieved from https://tspace.library.utoronto.ca/bitstream/1807/16282/1/MQ58767.pdf

Priestley, M., \& Kowalski, M. (1998). Aspects of Drift and Ductility Capacity of Cantiveler Structural Walls. Bulletin of the New Zealand National Society for Earthquake Engineering, 31(2).

Priestley, M. J. N., Calvi, G. M., \& Kowalsky, M. J. (2007). Displacement-based seismic design of structures / M. J. N. Priestley, Gian Michele Calvi, Mervyn J. Kowalsky: Pavia : IUSS Press : Fondazione Eucentre, 2007.

Priestley, M. J. N., \& Kowalsky, M. J. (1998). Aspects of drift and ductility capacity of rectangular cantilever structural walls (Vol. 31). Wellington, New Zealand: New Zealand National Society for Earthquake Engineering.

Priestley, M. J. N., \& Park, R. (1984). Strength and Ductility of Bridge Substructures. National Roads Board, Wellington, New Zealand: RRU Bulletin 71.

Priestley, M. J. N., Seible, F., \& Calvi, G. M. (1996). Seismic design and retrofit of bridges: New York : Wiley, c1996.

RLB. (2014). Riders Digest 2014 Adelaide, Australia Edition: Rider Levett Bucknall.

Sittipunt, C., \& Wood, S. L. (1993). Finite element analysis of reinforced concrete shear walls. Retrieved from

Smyrou, E., Sullivan, T., Priestley, N., \& Calvi, M. (2013). Sectional response of T-shaped RC walls. Bulletin of Earthquake Engineering, 11(4), 999-1019. doi:http://dx.doi.org/10.1007/s10518012-9407-2 
Sritharan, S., Beyer, K., Henry, R. S., Chai, Y. H., Kowalsky, M., \& Bull, D. (2014). Understanding Poor Seismic Performance of Concrete Walls and Design Implications. Earthquake Spectra, 30(1), 307-334. doi:10.1193/021713EQS036M

Standards Australia. (2009). AS 3600-2009: Concrete Structures.

Standards Australia/New Zealand. (2001). AS/NZS 4671:2001 : Steel Reinforcing Materials.

Sullivan, T. J., Priestley, M. J. N., \& Calvi, G. M. (2012). A Model Code for the Displacement-based Seismic Design of Structures. Pavia, Italy: IUSS Press.

Thomsen, J., \& Wallace, J. (2004). Displacement-Based Design of Slender Reinforced Concrete Structural Walls-Experimental Verification. Journal of Structural Engineering, 130(4), 618630. doi:doi:10.1061/(ASCE)0733-9445(2004)130:4(618)

Vecchio, F. (1992). Finite Element Modeling of Concrete Expansion and Confinement. Journal of Structural Engineering, 118(9), 2390-2406.

Vecchio, F., Lai, D., Shim, W., \& Ng, J. (2000). Disturbed Stress Field Model for Reinforced Concrete: Validation. Journal of Structural Engineering, 126(9), 1070.

Wallace, J. W., \& Moehle, J. P. (1992). Ductility and Detailing Requirements of Bearing Wall Buildings. Journal of Structural Engineering, 118(6), 1625-1644.

Wibowo, A., Wilson, C. J. N., Lam, N., \& Gad, E. (2016). Yield Penetration Displacement of Lightly Reinforced Concrete Columns. Applied Mechanics and Materials, 845, 119-125.

Wibowo, A., Wilson, J., Lam, N. T. K., \& Gad, E. F. (2013). Seismic performance of lightly reinforced structural walls for design purposes. Magazine of Concrete Research, 65, 809-828. Retrieved from

Wight, J. K., Jirsa, J. O., \& Corley, W. G. (1984). SP-084: Earthquake Effects on Reinforced Concrete Structures: U.S.- Japan Research. Special Publication, 84. doi:10.14359/14041

Wong, P., Vecchio, F., \& Trommels, H. (2013). Vector2 and FormWorks User Manual. Department of Civil Engineering, University of Toronto.

Wood, S., Stark, R., \& Greer, S. (1991). Collapse of Eight- Story RC Building during 1985 Chile Earthquake. Journal of Structural Engineering, 117(2), 600-619.

Wood, S. L. (1989). Minimum tensile reinforcement requirements in walls. ACI Structural Journal, 86(5), 582-591.

Zhang, Z. W., \& Li, B. (2014). Evaluation of seismic performance of slender L-shaped and T-shaped $R C$ structural walls. Paper presented at the Proceedings of the 2nd European conference on earthquake engineering and seismology. Paper. 